\title{
Overview of Venus orbiter, Akatsuki
}

\author{
M. Nakamura ${ }^{1}$, T. Imamura ${ }^{1}$, N. Ishii ${ }^{1}$, T. Abe ${ }^{1}$, T. Satoh ${ }^{1}$, M. Suzuki ${ }^{1}$, M. Ueno ${ }^{1}$, A. Yamazaki ${ }^{1}$, N. Iwagami ${ }^{2}$, S. Watanabe $^{3}$, \\ M. Taguchi ${ }^{4}$, T. Fukuhara ${ }^{3}$, Y. Takahashi ${ }^{3}$, M. Yamada ${ }^{1}$, N. Hoshino ${ }^{5}$, S. Ohtsuki ${ }^{1}$, K. Uemizu ${ }^{1}$, G. L. Hashimoto ${ }^{6}$,

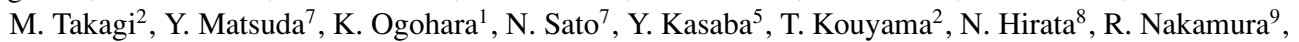 \\ Y. Yamamoto ${ }^{1}$, N. Okada ${ }^{1}$, T. Horinouchi ${ }^{10}$, M. Yamamoto ${ }^{11}$, and Y. Hayashi ${ }^{12}$ \\ ${ }^{1}$ Institute of Space and Astronautical Science, Japan Aerospace Exploration Agency, \\ 3-1-1 Yoshinodai, Chuo-ku, Sagamihara, Kanagawa 252-5210, Japan \\ ${ }^{2}$ Department of Earth and Planetary Science, The University of Tokyo, 7-3-1 Hongo, Bunkyo-ku, Tokyo 113-0033, Japan \\ ${ }^{3}$ Department of Earth Sciences, Hokkaido University, N10W8, Sapporo, Hokkaido 060-0810, Japan \\ ${ }^{4}$ Department of Physics, Rikkyo University, 3-34-1, Nishi-ikebukuro, Toshima-ku, Tokyo 171-8501, Japan \\ ${ }^{5}$ Department of Geophysics, Tohoku University, 6-3 Aramaki-aza-Aoba, Aoba-ku, Sendai, Miyagi 980-8578, Japan \\ ${ }^{6}$ Department of Earth Sciences, Okayama University, 3-1-1 Tsushima-Naka, Kita-ku, Okayama 700-8530, Japan \\ ${ }^{7}$ Department of Astronomy and Earth Sciences, Tokyo Gakugei University, 4-1-1 Nukuikitamachi, Koganei, Tokyo 184-8501, Japan \\ ${ }^{8}$ Research Center for Advanced Information Science and Technology, Tsuruga, Ikki-machi, Aizu-Wakamatsu, Fukushima 965-8580, Japan \\ ${ }^{9}$ National Institute of Advanced Industrial Science and Technology, 1-1-1 Umezono, Tsukuba 305-8568, Japan \\ ${ }^{10}$ Faculty of Environmental Earth Science, Hokkaido University, N10W5, Sapporo 060-0810, Japan \\ ${ }^{11}$ Research Institute for Applied Mechanics Kyushu University, 6-1 Kasuga-kouen, Kasuga-ku, Fukuoka 816-8580, Japan \\ ${ }^{12}$ Department of Earth and Planetary Sciences, Kobe University, 1-1 Rokkodai-cho, Nada-ku, Kobe 657-8501, Japan
}

(Received June 25, 2010; Revised February 10, 2011; Accepted February 15, 2011; Online published June 21, 2011)

The Akatsuki spacecraft of Japan was launched on May 21, 2010. The spacecraft planned to enter a Venusencircling near-equatorial orbit in December 7, 2010; however, the Venus orbit insertion maneuver has failed, and at present the spacecraft is orbiting the Sun. There is a possibility of conducting an orbit insertion maneuver again several years later. The main goal of the mission is to understand the Venusian atmospheric dynamics and cloud physics, with the explorations of the ground surface and the interplanetary dust also being the themes. The angular motion of the spacecraft is roughly synchronized with the zonal flow near the cloud base for roughly 20 hours centered at the apoapsis. Seen from this portion of the orbit, cloud features below the spacecraft continue to be observed over 20 hours, and thus the precise determination of atmospheric motions is possible. The onboard science instruments sense multiple height levels of the atmosphere to model the three-dimensional structure and dynamics. The lower clouds, the lower atmosphere and the surface are imaged by utilizing nearinfrared windows. The cloud top structure is mapped by using scattered ultraviolet radiation and thermal infrared radiation. Lightning discharge is searched for by high speed sampling of lightning flashes. Night airglow is observed at visible wavelengths. Radio occultation complements the imaging observations principally by determining the vertical temperature structure.

Key words: Venus, meteorology, exploration.

\section{Introduction}

Akatsuki (Planet-C project) is Japan's third planetary explorer succeeding Suisei (Planet-A), which observed Halley's comet, and Nozomi (Planet-B), which could not complete its mission to explore Mars. 'Akatsuki' is a Japanese word meaning 'dawn', and the spacecraft is also called the Venus Climate Orbiter. The results achieved from the interplanetary navigations in the Suisei, Nozomi, Hiten (Muses-A) and Hayabusa (Muses-C) missions are utilized in this project. Akatsuki was successfully launched on May 21, 2010 using the H-IIA Launch Vehicle No. 17. After the separation from H-IIA, the telemetry from Akatsuki was normally detected by the Deep Space Network (DSN) Goldstone station and the solar cell paddles' expansion was

Copyright (C) The Society of Geomagnetism and Earth, Planetary and Space Sciences (SGEPSS); The Seismological Society of Japan; The Volcanological Society of Japan; The Geodetic Society of Japan; The Japanese Society for Planetary Sciences; TERRAPUB.

doi:10.5047/eps.2011.02.009 confirmed. Akatsuki was put into the three-axis stabilized mode in the initial operation from the Japan's Uchinoura station and the critical operation was finished on the same day.

Venus is one of the most attractive targets in the solar system when we seek to understand how terrestrial planets differentiate into various types. Venus is our nearest neighbor, and has a size very similar to the Earth's. However, previous spacecraft missions discovered an extremely dense ( $~ 92$ bar) and dry $\mathrm{CO}_{2}$ atmosphere with $\mathrm{H}_{2} \mathrm{SO}_{4}-\mathrm{H}_{2} \mathrm{O}$ clouds floating at $45-70 \mathrm{~km}$ altitudes, and exotic volcanic features covering the whole planet. The abundant gaseous $\mathrm{CO}_{2}$ brings about a high atmospheric temperature $(\sim 740 \mathrm{~K})$ near the surface via greenhouse effect. The atmospheric circulation is also much different from the Earth's as described in Section 2.

The former Soviet Union sent many probes to Venus from the 1960 s to the 1980 s. Their Venera series used entry probes and orbiters to study the atmospheric composition 
and structure, surface composition, and topography (Moroz, 1983). Although the surface of Venus was too hot for the entry probes to survive for more than two hours, their observations gave us a rough idea about the Venusian environment. The Pioneer Venus orbiter and entry probes of U.S., which were launched in 1978, also provided plenty of new information on the atmosphere and the surface (Colin, 1980). The Vega balloons were dropped into the cloud layer of Venus by the Soviet Union and France in 1985 and observed meso-scale cloud processes and horizontal advection over 46 hours (Sagdeev et al., 1986). The U.S. probe Magellan, which took off for Venus in 1989, radar-mapped the Venusian surface precisely (Saunders et al., 1992). In 1990, the Galileo spacecraft encountered Venus for a gravity assist to obtain kinetic energy to go to Jupiter, and at that time, it observed the Venus atmosphere (Johnson et al., 1991).

After these missions, the exploration of Venus was interrupted for more than 10 years, in spite of the fact that most of the fundamental questions raised so far still remain unsolved. This is partly because people were focusing on Mars and the Moon as places that are easier for human beings to land on. It was not until the 21 st century that Venus exploration was restarted. The Europeans were first out of the gate; the European Space Agency (ESA) developed and launched Venus Express in a very short time, in November 2005, by reusing designs from Mars Express, which had already taken off (Svedhem et al., 2007). Akatsuki was developed almost in parallel with Venus Express.

Akatsuki aims to solve the mystery of the atmospheric circulation and cloud formation of Venus, with secondary targets being the exploration of the ground surface and the zodiacal light observation during the cruise to Venus. The exploration of the Venusian meteorology is important not only for understanding the climate of Venus but also for a general understanding of planetary fluid dynamics. Akatsuki will explore the Venusian atmosphere using a set of sophisticated optical instruments dedicated to meteorological study and radio occultation technique. Such an approach complements the Venus Express mission, which also aims to understand the Venusian environment with a different approach.

The Venus orbit insertion maneuver for Akatsuki on December 7, 2010 has failed. At present the spacecraft is orbiting the Sun, and it will have a chance to encounter Venus 5 or 6 years later. JAXA is examining the possibility of conducting an orbit insertion maneuver again at this opportunity. The present paper briefly introduces the Akatsuki's science goals, mission design, science instruments, observation plan, and the relationship with Venus Express; these will be largely unchanged in the renewed plan. The details of the science instruments are given in the accompanying papers.

\section{Scientific Background \\ 2.1 Super-rotation}

The principal mode of the atmospheric circulation of Venus is a zonal westward rotation of the entire atmosphere called the super-rotation (Schubert, 1983). The wind speed increases with height and reaches $\sim 100 \mathrm{~m} \mathrm{~s}^{-1}$ near the cloud top ( $\sim 65 \mathrm{~km}$ altitude), while the solid planet rotates in the same direction very slowly with a period of 243 Earth days corresponding to an equatorial rotation speed of $1.6 \mathrm{~m} \mathrm{~s}^{-1}$. Because of this rapid rotation of the atmosphere, the wind field and the temperature field are considered in a cyclostrophic balance, where the horizontal projection of the centrifugal force is equal to the meridional pressure gradient. The zonal wind velocity at the cloud top is fairly constant in the latitude range of $50^{\circ} \mathrm{S}-50^{\circ} \mathrm{N}$, while it is near solid-body rotation (constant angular velocity) below $\sim 40 \mathrm{~km}$ altitude. Prominent mid-latitude jets are seen at cloud heights especially in the wind field derived from the temperature distribution by integrating the thermal wind equation assuming cyclostrophic balance (Newman et al., 1984). Since eddy viscosity should transport angular momentum downward and pass it to the solid planet, some mechanism which extracts angular momentum from the solid planet and transports it to the upper atmosphere is required to maintain the easterly vertical shear associated with the super-rotation.

Various mechanisms explaining the super-rotation have been proposed so far (Gierasch et al., 1997). Among them is the combination of a thermally-driven Hadley circulation and axiasymmetric disturbances (eddies) which transport angular momentum equatorward (Gierasch, 1975). In this mechanism an upward branch of the Hadley cell transports larger angular momentum than the downward branch, thereby accumulating angular momentum at higher levels. Two-dimensional models predict that barotropic instability of mid-latitude jets will cause equatorward transport of angular momentum (Rossow and Williams, 1979; Iga and Matsuda, 2005). However, the mode of eddy momentum transport in a three-dimensional atmosphere is unclear. The prominent mid-latitude wave mode with a 5day period seen at the cloud top (Del Genio and Rossow, 1990) might be generated via the instability of mid-latitude jets. Cloud-tracked wind data suggests poleward eddy momentum transport and a resultant equatorial deceleration (Limaye et al., 1988; Rossow et al., 1990), although the absence of wind measurements on the nightside might cause a bias in the estimation of the momentum transport.

Atmospheric general circulation models for Venus-like slowly rotating planets seem to favor this process as the mechanism of maintaining the super-rotation (Del Genio and Zhou, 1996; Yamamoto and Takahashi, 2003, 2006; Lee et al., 2007; Kido and Wakata, 2008). However, these models assume either an unrealistically high solar heating rate in the deep atmosphere or an unrealistically large equator-to-pole surface temperature gradient so that a strong Hadley circulation can exist in the deep atmosphere. Hollingsworth et al. (2007) argued that this mechanism would induce only extremely weak super-rotation when realistic diabatic heating is imposed in the lowest several scale heights. Improvements in the treatment of radiative transfer in the lower atmosphere are strongly needed.

Vertically-propagating waves might also induce vertical momentum transport. Thermal tides will be excited in the cloud layer by periodic solar heating and propagate both upward and downward (Fels and Lindzen, 1974; Newman and Leovy, 1992). Thermal tides reaching the ground surface would give negative angular momentum to the solid 
planet, and at the same time the atmosphere is accelerated. The difficulty of this mechanism has been thought that the dissipation of the tides will generate critical layers below the cloud to inhibit further momentum transport. However, Takagi and Matsuda $(2005,2007)$ argued that such waves reach the surface without being dissipated significantly. Diurnal and semidiurnal tides are observed in the temperature structure above clouds (Taylor et al., 1980; Zasova et al., 2002; Tellmann et al., 2009) and in the cloud-top wind field (Rossow et al., 1990), while propagation to the lower atmosphere has not yet been observed.

It might also be possible that equatorial Kelvin waves or internal gravity waves are excited in the lower atmosphere and transport angular momentum upward (Del Genio and Rossow, 1990; Yamamoto and Tanaka, 1997). Note, however, that the vertical extent of the momentum transport associated with these waves is unknown. Covey and Schubert (1982) studied the linear response of a model Venus atmosphere to external forcing over broad frequencies, and showed that a Kelvin-like wave similar to the observed one will be excited as a preferred mode for both cloud-level and surface-level forcing. Smith et al. (1993) argued that adding a cloud feedback heating to the model greatly enhance a Kelvin-like wave, which shows standing behavior below $53 \mathrm{~km}$ altitude and upward propagation above. The specific disturbance that provides energy to the Kelvin wave has not been identified. Small-scale atmospheric structures indicative of internal gravity waves were observed in temperature profiles (Hinson and Jenkins, 1995) and in cloud images (Markiewicz et al., 2007; Peralta et al., 2008). Oscillating vertical winds encountered by Vega balloons over highlands are attribute to orographically-excited gravity waves (Sagdeev et al., 1986); orographic waves, however, should transport eastward momentum upward and decelerate the super-rotation.

The difficult situation described above is in large part attributed to the lack of information on the synoptic- to planetary-scale waves that induce angular momentum transport. The relationship between the activities of such waves and the temporal variability of the background zonal wind would provide key information. The structure of the meridional circulation (Section 2.2) should also be known.

\subsection{Meridional circulation}

Meridional circulation is an important issue not only in the momentum balance of the super-rotation but also from the viewpoint of the thermal balance and the chemical cycle of the atmosphere. Vertically-stacked direct and indirect cells have been proposed based on the wind measurements by entry probes (Schubert et al., 1980). However, it is possible that the observed meridional winds are not mean meridional circulation but transient eddies, although verticallystaked cells are considered reasonable for the Venusian atmosphere where the solar energy is deposited not only near the surface but also in the cloud layer.

Another observational clue is a poleward circulation with a speed of $\sim 10 \mathrm{~m} \mathrm{~s}^{-1}$ observed at the dayside cloud top by cloud tracking (Limaye and Suomi, 1981; Rossow et al., 1990; Moissl et al., 2009). However, the limited local time coverage in these observations may allow a significant contamination of the thermal tide component, which can be up to $\sim 10 \mathrm{~m} \mathrm{~s}^{-1}$ (Newman and Leovy, 1992). At lower heights ( $\sim 50 \mathrm{~km}$ ), cloud tracking using near-infrared wavelengths suggests a much weaker circulation, which is below the detection limit of these measurements of a few $\mathrm{m} \mathrm{s}^{-1}$ (Belton et al., 1991; Sánchez-Lavega et al., 2008). The adiabatic heating of the high latitude stratosphere above the cloud, which is suggested by the temperature increase at high latitude (Crisp, 1989; Pätzold et al., 2007), and the increased $\mathrm{CO}$ mixing ratio in the high-latitude below the cloud layer (Collard et al., 1993; Tsang et al., 2008) are thought to be attributed to the downward branch of the cloud-level Hadley circulation.

The structure of the meridional circulation might be determined by the distribution of wave-induced acceleration and deceleration (Hou and Goody, 1989). Imamura (1997) argued that the momentum deposition by midlatitude Rossby waves might drive the poleward circulation above clouds. Numerical model results suggest that only extremely weak meridional circulation can exist at lower heights when a realistic diabatic heating is imposed in the lowest several scale heights (Hollingsworth et al., 2007). Stone (1974) argued that the heat transport by a direct (Hadley) circulation will explain the observed approximately neutral (but slightly stable) stratification of the lower atmosphere.

The cloud-top poleward circulation will supply angular momentum to the polar region to maintain the polar vortex and bring about the polar dipole by initiating barotropic instability (Taylor et al., 1980; Elson, 1982). The dipole structure extends down to the lower cloud and perhaps deeper (Piccioni et al., 2007). The barotropic eddies creating the dipole will impose an eastward torque on the polar vortex which is basically in cyclostrophic balance, thereby driving the influx of air into the polar region and downward into the lower atmosphere. The polar dipole might play a key role in the air exchange across the cloud layer.

Vertical transport of air and momentum will occur also via small-scale turbulence. Woo et al. (1980) analyzed the time series of the signal power observed during radio occultations and compared their spectra with theoretical scintillation spectra based on a theory of wave propagation through small-scale density structures. They found that a turbulent layer exists around $60 \mathrm{~km}$ altitude, and the scintillation power is higher at higher latitudes. An eddy diffusion coefficient of $4 \mathrm{~m}^{2} \mathrm{~s}^{-1}$ was estimated for $60 \mathrm{~km}$ altitude from the same data set. Leroy and Ingersoll (1996), on the other hand, attributed the scintillations to vertically-propagating gravity waves created by cloud-level convection.

\subsection{Thermosphere and ionosphere}

In the thermosphere, a large pressure difference between the dayside and the nightside leads to a subsolar-to-antisolar circulation (Bougher et al., 1997). The shift of the brightest regions of night airglows toward the dawn suggests that the thermospheric circulation is a combination of a subsolarto-antisolar flow and a super-rotation (Allen et al., 1992). Seiff (1982) suggested that the subsolar-to-antisolar flow would become supersonic if only the acceleration by the pressure gradient force is considered, and that the observed flow speed of $\sim 100 \mathrm{~m} \mathrm{~s}^{-1}$ suggests a deceleration by waveinduced drag. The strengths of the subsolar-to-antisolar 
flow and super-rotation change from time to time; the observed variability of the distribution of airglows indicates the variability of the thermospheric circulation (Crisp et al., 1996; Ohtsuki et al., 2008), which might be due to the variability in the momentum deposition by gravity waves. A comparative study of the thermospheric circulation and the lower atmosphere circulation will offer clues to the question why zonal circulation dominates in the lower atmosphere in such a slowly-rotating planet.

At altitudes above $\sim 100 \mathrm{~km}$ the thermosphere merges into the ionosphere. The peak electron density occurs at around $150 \mathrm{~km}$ altitude, and is on the order of $10^{5} \mathrm{~cm}^{-3}$ on the dayside and $10^{4} \mathrm{~cm}^{-3}$ on the nightside (Kliore, 1992). The ionosphere of Venus is not protected by the planet's intrinsic magnetic field from the impinging solar wind, and thus the thermal and magnetic pressure of the ionosphere will balance the dynamic pressure of the solar wind at the upper boundary of the ionosphere called the ionopause, which is located at around $200-400 \mathrm{~km}$. The structure of the ionosphere is important for understanding the escape of the atmosphere to space, which should have driven the climate evolution of Venus in a geological time scale.

\subsection{Clouds and lightning}

The energy budget and chemical cycle of the Venusian atmosphere is strongly influenced by the highly reflective $\mathrm{H}_{2} \mathrm{SO}_{4}-\mathrm{H}_{2} \mathrm{O}$ clouds, which float at around $45-70 \mathrm{~km}$ altitudes (Esposito et al., 1983). $\mathrm{H}_{2} \mathrm{SO}_{4}$ is thought to be produced photochemically near the cloud top via the oxidation of $\mathrm{SO}_{2}$ and $\mathrm{H}_{2} \mathrm{O}$, which are abundant below the cloud top, and thus the clouds basically have characteristics of photochemical aerosols. Cloud droplets are transported to the lower atmosphere by vertical winds and sedimentation, and eventually evaporate to produce $\mathrm{H}_{2} \mathrm{SO}_{4}$ vapor layer, which drives chemical cycles below the clouds (Krasnopolsky and Pollack, 1994). Radio occultation measurements showed that the $\mathrm{H}_{2} \mathrm{SO}_{4}$ vapor density reaches the maximum value of $18-24 \mathrm{ppm}$ around $38-45 \mathrm{~km}$ altitude (Jenkins et al., 1994). Above this altitude the density is limited by the saturation pressure, while below this altitude it drops precipitously probably due to thermal decomposition.

A strong coupling between cloud condensation and atmospheric motion is also expected to occur in the lower part of the cloud layer $(50-55 \mathrm{~km})$. The heating of clouds by upwelling infrared radiation drives vertical convection, while vertical convection enhances cloud formation by transporting $\mathrm{H}_{2} \mathrm{SO}_{4}$ vapor upward (Imamura and Hashimoto, 2001; McGouldrick and Toon, 2007). The static stability is near neutral in this region, implying the occurrence of vertical convection (Fjeldbo et al., 1971; Tellmann et al., 2009). What determines the vertical extent and the density of the convectively-generated clouds is a major issue in the cloud physics of Venus.

The cell-like structures observed at the cloud top near the sub-solar region in ultraviolet (Rossow et al., 1980; Markiewicz et al., 2007) are indicative of the convection inside clouds mentioned above. However, the origin of these structures are still unclear, because their horizontal scales of up to several hundreds kilometers seem to be too large for convective cells and the cloud top region is considered to be stably stratified (Baker and Schubert, 1992; Toigo et al.,
1994). Observations of the three-dimensional cloud structure together with the temperature structure over a broad local time would give clues to this problem.

The global-scale meridional circulation of the atmosphere might also determine the life cycle of cloud particles and the cloud structure, because the sedimentation timescale of cloud particles with a typical diameter of a few micrometers (Knollenberg and Hunten, 1980) will be longer than the atmospheric turnover time of a few months estimated from cloud tracking (Imamura and Hashimoto, 1998; Yamamoto and Tanaka, 1998). Imamura and Hashimoto (1998) argued that $\mathrm{H}_{2} \mathrm{SO}_{4}$ vapor is accumulated near the equatorial cloud base due to the precipitation in the equatorial upwelling and that this leads to the thickening of the lower cloud which was observed by entry probes. The interaction of cloud physics with various atmospheric motions will be reflected in the mysterious ultraviolet markings at the cloud top, whose dynamical origins are mostly unknown (Rossow et al., 1980).

The chemical species that are responsible for the ultraviolet dark regions have not yet been fully identified. Although $\mathrm{SO}_{2}$ explains the absorption at wavelengths between $200 \mathrm{~nm}$ and $320 \mathrm{~nm}$, the absorption at $>320 \mathrm{~nm}$ should be due to another absorber. The candidates for this absorber include $\mathrm{S}, \mathrm{S}_{2} \mathrm{O}$ and $\mathrm{FeCl}_{2}$ (Esposito et al., 1997). The mixing ratios of these absorbers are considered to increase precipitously with decreasing the altitude below the cloud top (Pollack et al., 1980). Identification of the absorber is important not only for atmospheric chemistry but also for the radiative energy budget, since the absorption makes a nonnegligible contribution to the heating profile in the cloud layer (Ekonomov et al., 1984).

Lightning discharge is closely related to cloud formation and can be an indicator of vigorous convective activity. Lightning also potentially influences atmospheric chemistry via chemical reactions along discharge paths. The occurrence of lightning in the Venusian atmosphere has been suggested by various observations (Grebowsky et al., 1997). Recently the Venus Express magnetometer also detected whistler-mode electromagnetic waves which might come from lightning discharges (Russell et al., 2007). However, the occurrence is still under debate since the conventional mechanism of charge separation in terrestrial clouds requires $\mathrm{H}_{2} \mathrm{O}$ ice particles, which will not be formed in the Venusian atmosphere. Large solid particles of unknown composition suggested by the particle size spectrometer on the Pioneer Venus probe (Knollenberg and Hunten, 1980) might play some role.

\subsection{Surface processes}

The composition and abundance of the Venusian atmosphere might be controlled by the chemical coupling with the crust (Fegley et al., 1997; Wood, 1997). One possibility is that the atmospheric $\mathrm{CO}_{2}$ abundance is determined by the equilibrium partial pressure over a calcite-quartzwollastonite assemblage. However, this model has difficulties that a climate system under this equilibrium would be unstable and that the observed $\mathrm{SO}_{2}$ mixing ratio in the lower atmosphere is inconsistent with the presence of calcite on the surface if no volcanic source of $\mathrm{SO}_{2}$ is considered (Hashimoto and Abe, 2005). It has also been pro- 
posed that the atmospheric $\mathrm{SO}_{2}$ mixing ratio is in equilibrium with a pyrite-magnetite assemblage. This chemical coupling would stabilize the climate through a cloud-albedo feedback (Hashimoto and Abe, 2000). Anomalous radar reflectivity areas observed at Venusian highlands might be attributed to pyrite produced by the atmosphere-surface interaction above, although heavy metal frost may also explain the reflectivity (Schaefer and Fegley, 2004). Near-infrared imaging spectroscopy has a potential to improve our knowledge on the chemical coupling through constraining the spatial inhomogeneity of the surface material (Hashimoto and Sugita, 2003).

Venus may have experienced large environmental changes. The redox state of Venus surface is an important parameter, since redox state of the surface is likely related to the escape of water. Hashimoto et al. (2008) evaluated the spatial variation of the surface emissivity at $1.18 \mu \mathrm{m}$ wavelength using spectroscopic data, and showed that the data of highland materials are generally consistent with a felsic rock composition, possibly indicative of an ancient ocean.

The thermal evolution and chemical differentiation of a terrestrial planet is related to volcanism. Its climate and surface environment are also controlled by volcanism in that the associated degassing affects the atmospheric composition producing climate variations (Hashimoto and Abe, 2000). The current rate of volcanism, which is a key parameter determining the present chemical state of the atmosphere, is uncertain (Basilevsky et al., 1997). Nearinfrared imaging will be a valuable tool also for constraining the state of volcanism via the search for active volcanoes (Hashimoto and Imamura, 2001).

\subsection{Interplanetary dust}

The zodiacal light, i.e. the interplanetary dust (IPD) cloud, is observed in the cruising phase of the mission. A major issue in the IPD cloud is its origin, since the lifetime of IPD particles under the Poynting-Robertson drag is absolutely shorter than the age of the solar system.

Imaging observation is one of the effective approaches to study the origins of the IPD clouds, since the IPD clouds keep the morphological structures of their sources, that is, the particles must have the same orbital elements as their parents have. Observations of zodiacal light took the first step in ground-based measurements at visible wavelength; however, early photoelectric observations suffered from calibration uncertainty and poor spatial resolution. All-sky maps of the zodiacal light brightness at visible band have now reached a relative accuracy better than $10 \%$ and a spatial resolution of 2 arcmin. The accuracy and spatial resolution are being improved drastically by the WIZARD project (Ishiguro et al., 2002).

The Infrared Astronomical Satellite (IRAS) outdated the smooth featureless pictures of the zodiacal light by revealing numerous bands of asteroidal debris, several narrow trails of cometary dust, and a clumpy dust ring (Dermott et al., 1984; Sykes and Greenberg, 1986; Sykes and Walker, 1992). The ring clumps comprise always the same configuration in the frame rotating at the rate of the Earth's orbital motion. The success of IRAS was largely due to the improvements in the relative accuracy and spatial resolution, that were made possible by the measurements free from the Earth's scattering atmosphere.

The Cosmic Background Explorer (COBE) Diffuse Infrared Background Experiment (DIRBE) surveyed almost the entire sky with a $0.7^{\circ}$ size beam and with much better calibration (Kelsall et al., 1998). One of the most important results of this mission is a confirmation of the mean motion resonance dust ring, and an isolation of the leading and trailing blobs in the mean motion resonance feature.

\section{Spacecraft Design and Orbit}

The configuration of the Akatsuki spacecraft is shown in Fig. 1. The spacecraft is three-axis stabilized by four momentum wheels and directs cameras toward Venus via the attitude control of the main body. The spacecraft surfaces on which solar array paddles are attached always face to the north or the south, and are used for radiative cooling. The solar array paddles have one freedom of rotation about the north-south axis, and their orientations are controlled to face to the sun independent of the orientation of the main body. The two X-band flat-type high gain antennas, one of which is for transmission $(8.4 \mathrm{GHz})$ and the other is for reception $(7.1 \mathrm{GHz})$, will be oriented toward the Earth by the attitude control of the spacecraft when communicating with the tracking station. The telemetry rate changes with the Earth-Venus distance; it will be $32 \mathrm{kbps}$ (kilobits per second) for $0.3 \mathrm{AU}$, while it will be $16 \mathrm{kbps}$ for $1.7 \mathrm{AU}$. The mass of the spacecraft is $\sim 500 \mathrm{~kg}$ including fuel, and the science payload weighs $\sim 35 \mathrm{~kg}$.

The camera field of view (FOV) is directed toward targets by using the attitude control of the spacecraft. The pointing accuracy is $0.15^{\circ}(1 \sigma)$, which is much smaller than the camera FOVs of $12-16^{\circ}$ (Section 4$)$. The attitude stability is $0.01^{\circ}$ or better up to 45 seconds except shortly after attitude maneurvers or unloadings of the momentum wheels. This stability allows cameras with pixel resolutions of $0.012^{\circ}$ to avoid significant blurring of images. The attitude determining accuracy is around $0.01^{\circ}$ or worse, and thus the redetermination of the camera FOVs by limb fitting technique is needed for precise cloud tracking (Section 6).

Akatsuki was launched in May 20 (UT), 2010 and directly went into the interplanetary space without passing through a phasing orbit (Fig. 2). During the cruise to Venus, Akatsuki observed the zodiacal light without any contaminations of the sky light, and got information on the spatial distribution of the IPD cloud. The Venus orbit insertion was scheduled for early December in the same year; however, the arrival was postponed for several years (Section 1). The minimum mission life at Venus will be 2 Earth years; the mission life will be determined by the degradation of the onboard lithium-ion batteries, which are needed to survive the eclipse period which is up to $\sim 90$ minutes per orbital revolution. The details of the mission design are given in Ishii et al. (2004).

The planned orbit around Venus is a 30 hour-period elliptical orbit near the ecliptic plane with the periapsis latitude of $\sim 10.5^{\circ} \mathrm{S}$ and the apoapsis latitude of $\sim 10.5^{\circ} \mathrm{N}$ (Fig. 3). The direction of orbital motion is westward, which is the same as the atmospheric super-rotation. The periapsis altitude is $370-840 \mathrm{~km}$ and the apoapsis altitude is 


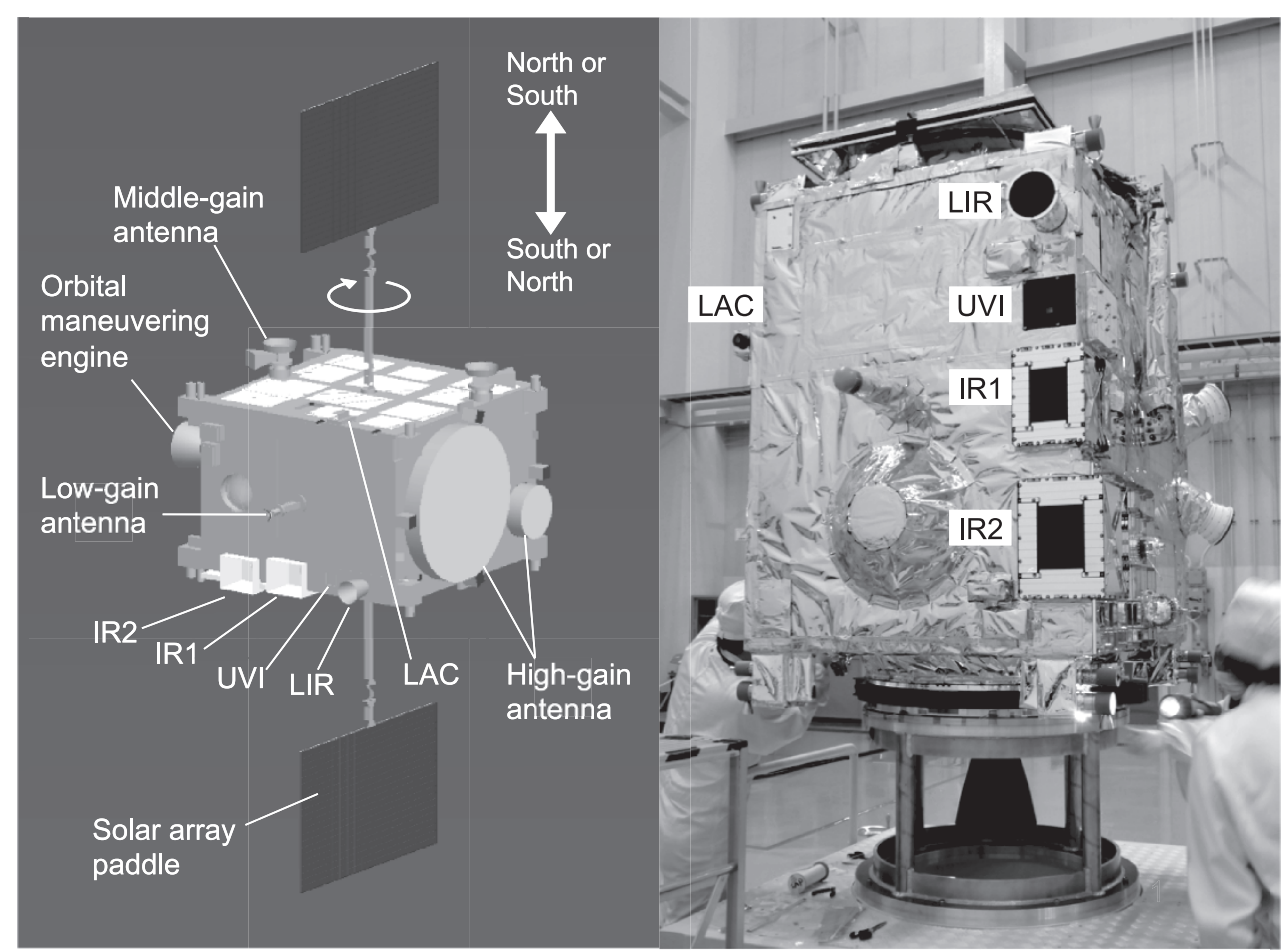

Fig. 1. Configuration of Akatsuki spacecraft (left) and a photograph of the spacecraft with the solar array paddles being folded (right).

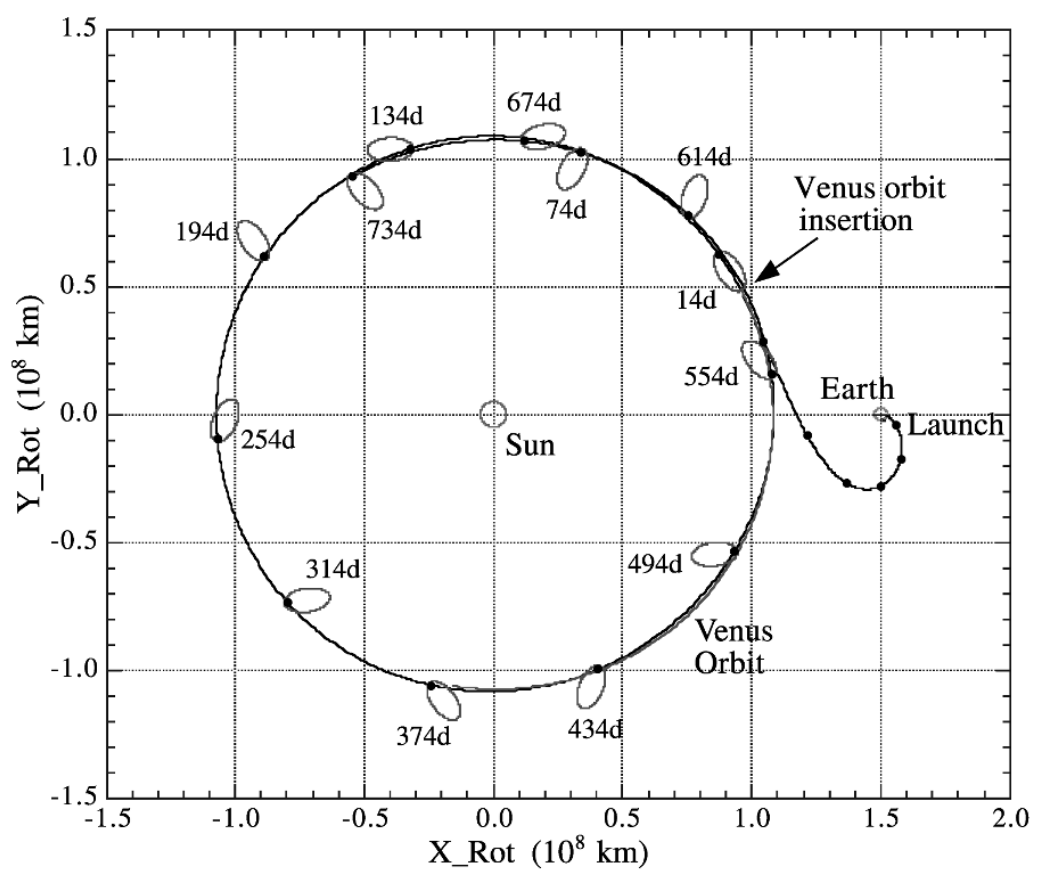

Fig. 2. Movement of the spacecraft orbit and Venus in a Sun-Earth line fixed rotating coordinate in the original plan. Numerals in the figure indicate days after VOI.

chosen to be $78500 \mathrm{~km}$, or 13 Venus radii (Rv), so that the angular motion of the spacecraft is roughly synchronized with the $60 \mathrm{~m} \mathrm{~s}^{-1}$ super-rotational flow near the cloud base $(50 \mathrm{~km})$ for roughly 20 hours centered at the apoapsis (Fig. 4). During this 20 hours both the spacecraft and the atmosphere travel $\sim 40^{\circ}$ in longitude. Seen from this 'quasi-synchronized' portion of the orbit, the cloud features below the spacecraft continue to be observed over 20 hours, and thus the precise determination of atmospheric motions is possible. This portion of the orbit roughly corresponds to the region where the angular diameter of the Venus disk is smaller than the typical camera FOV of $12^{\circ}$ (Fig. 3). Since the orientation of the major axis of the orbit is roughly fixed in a inertial coordinate, the local time of the apoaposis changes in the course of the revolution of Venus around the sun (Fig. 2). 

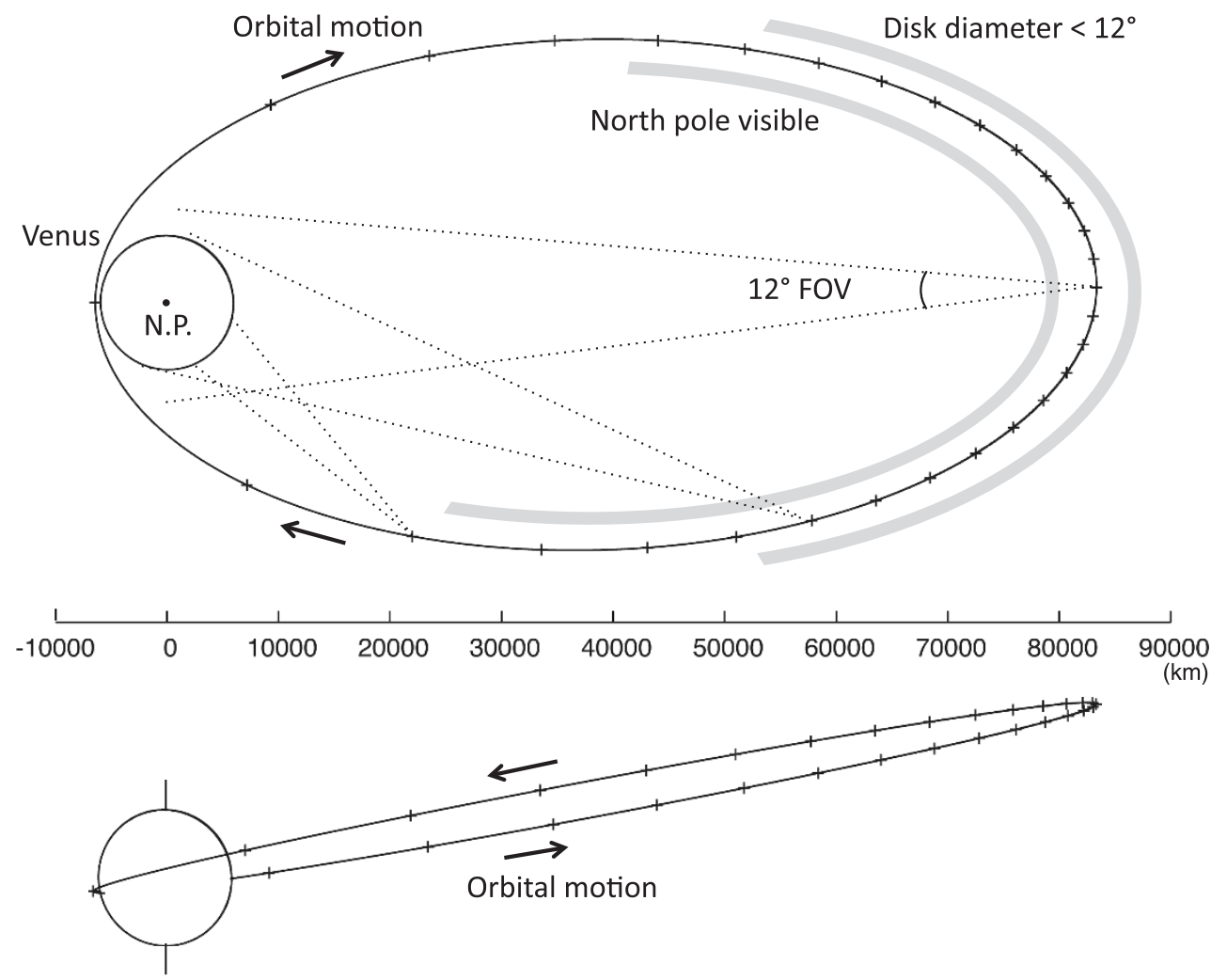

Fig. 3. Spacecraft orbit about Venus seen from the north (upper) and from the equatorial plane (lower). Spacecraft positions at every 1 hour are indicated by crosses. The region where the angular diameter of the Venus disk as seen from the spacecraft is smaller than typical camera FOV of $12^{\circ}$ and the region where the North pole is visible from the spacecraft are indicated by shades. The limb height seen from the spacecraft is assumed to be $80 \mathrm{~km}$.

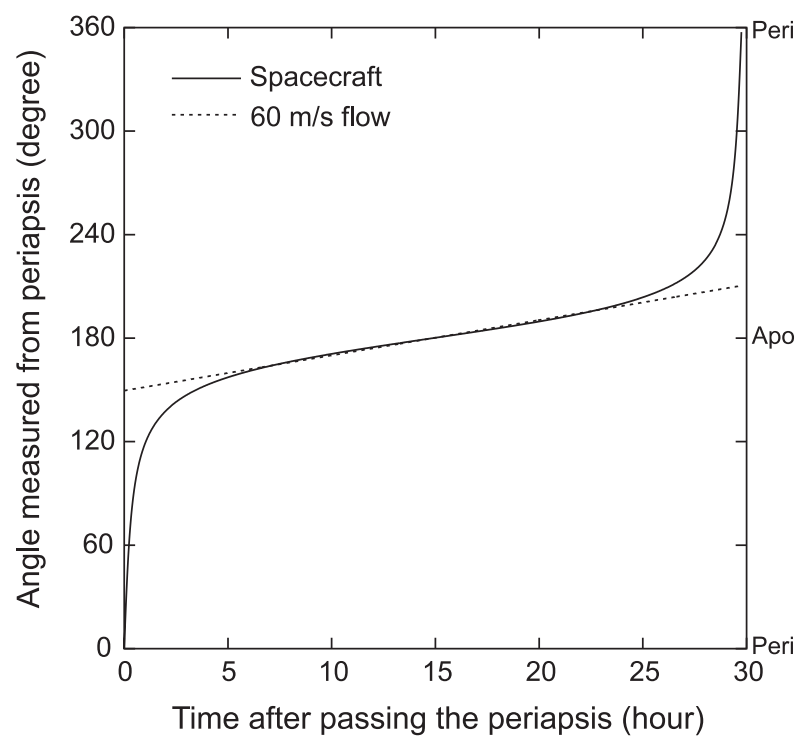

Fig. 4. Angular motion of the spacecraft relative to the center of Venus (solid), plotted with a curve for the constant westward flow of $60 \mathrm{~m} \mathrm{~s}^{-1}$ (dotted).

\section{Science Instruments}

The onboard science instruments altogether sense multiple height levels of the atmosphere to model the threedimensional structure and dynamics (Fig. 5). The lower atmosphere and the surface on the nightside are investigated by the $1-\mu \mathrm{m}$ Camera (IR1). The altitude region from the middle and lower clouds to $10 \mathrm{~km}$ below the cloud base on the nightside is covered by the $2-\mu \mathrm{m}$ Camera (IR2). The dayside middle and lower clouds are mapped by IR1. The dayside cloud top is observed principally by the Ultraviolet Imager (UVI) and also by IR2. The Longwave Infrared Camera (LIR) has an ability to observe the cloud top of both dayside and nightside. The Lightning and Airglow Camera (LAC) searches for lightning and maps airglows on the nightside. Radio Science (RS) complements the imaging observations principally by determining the vertical temperature profile and its spatial and temporal variabilities. The typical altitude levels probed by the infrared wavelengths are discussed by Takagi and Iwagami (2011).

IR1, IR2, UVI and LIR are cameras with large-format detector arrays, and have much common features in the image data format. They are operated sequentially as a unit in many cases as described in Section 5. For these reasons, a dedicated camera control unit called the Digital Electronics unit (DE) was developed to conduct sequential exposures using these cameras and to process the image data from these cameras before storing them in the data recorder.

The basic specifications of the cameras are summarized in Table 1 . The cameras have FOVs of $12^{\circ}$ or larger; given a FOV of $12^{\circ}$, the full disk of Venus can be captured in one image at distances of $>8.5 \mathrm{Rv}$ (Fig. 3). Brief descriptions of the science instruments, including $\mathrm{DE}$, are given below.

\section{$4.1 \quad 1-\mu \mathrm{m}$ Camera (IR1)}

IR1 (Iwagami et al., in press) was designed to image the dayside of Venus at $0.90 \mu \mathrm{m}$ wavelength and the nightside at $0.90,0.97$ and $1.01 \mu \mathrm{m}$ wavelengths, which are located in the atmospheric windows (Taylor et al., 1997). These 


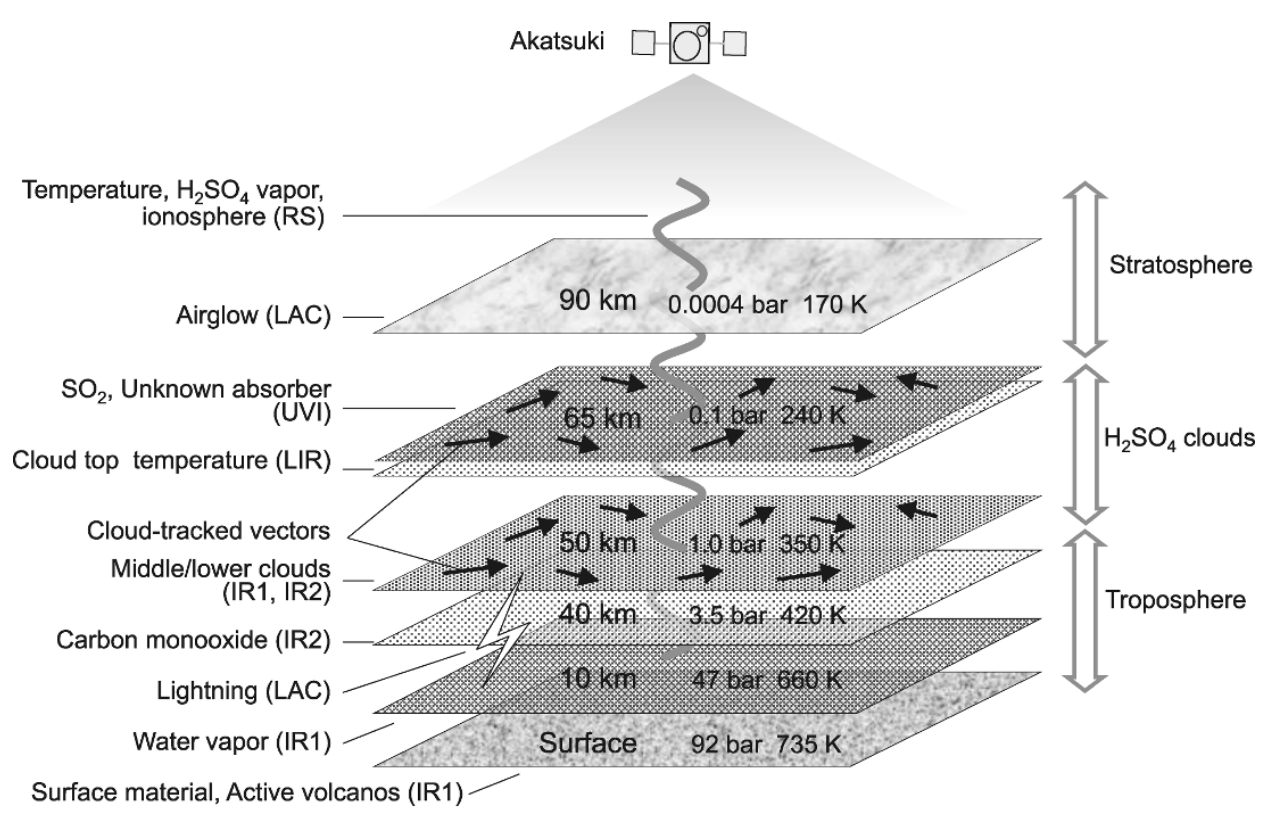

Fig. 5. Schematic of the three-dimensional observation by Akatsuki.

Table 1. Basic specifications of the cameras onboard Akatsuki.

\begin{tabular}{|c|c|c|c|c|c|}
\hline Name & FOV (deg) & Detector & Filters & Bandwidth & Targets \\
\hline \multirow[t]{4}{*}{ IR1 } & \multirow[t]{4}{*}{$12 \times 12$} & \multirow{4}{*}{$\begin{array}{l}\text { Si-CSD/CCD } \\
1024 \times 1024 \text { pixels }\end{array}$} & $1.01 \mu \mathrm{m}$ (night) & $0.04 \mu \mathrm{m}$ & Surface, Clouds \\
\hline & & & $0.97 \mu \mathrm{m}$ (night) & $0.04 \mu \mathrm{m}$ & $\mathrm{H}_{2} \mathrm{O}$ vapor \\
\hline & & & $0.90 \mu \mathrm{m}$ (day) & $0.01 \mu \mathrm{m}$ & Clouds \\
\hline & & & $0.90 \mu \mathrm{m}$, Diffuse & $0.01 \mu \mathrm{m}$ & (Flat field) \\
\hline \multirow{3}{*}{ IR2 } & \multirow{3}{*}{$12 \times 12$} & \multirow{3}{*}{$\begin{array}{l}\text { PtSi-CSD/CCD } \\
1024 \times 1024 \text { pixels }\end{array}$} & $2.32 \mu \mathrm{m}$ (night) & $0.04 \mu \mathrm{m}$ & CO below clouds \\
\hline & & & $2.02 \mu \mathrm{m}$ (night) & $0.04 \mu \mathrm{m}$ & Cloud-top height \\
\hline & & & $1.65 \mu \mathrm{m}$ (night) & $0.3 \mu \mathrm{m}$ & Zodiacal light \\
\hline UVI & $12 \times 12$ & $\begin{array}{l}\text { Si-CCD } \\
1024 \times 1024 \text { pixels }\end{array}$ & $283 \mathrm{~nm}$ (day) & $13 \mathrm{~nm}$ & $\mathrm{SO}_{2}$ at cloud top \\
\hline \multirow[t]{4}{*}{ LAC } & \multirow[t]{4}{*}{$16 \times 16$} & \multirow{4}{*}{$\begin{array}{l}\text { multi-anode APD } \\
8 \times 8 \text { pixels }\end{array}$} & $777.4 \mathrm{~nm}$ (night) & $8 \mathrm{~nm}$ & OI lightning \\
\hline & & & $480-605 \mathrm{~nm}$ (night) & $125 \mathrm{~nm}$ & $\mathrm{O}_{2}$ Herzberg II airglow \\
\hline & & & $557.7 \mathrm{~nm}$ (night) & $5 \mathrm{~nm}$ & OI airglow \\
\hline & & & $545.0 \mathrm{~nm}$ (night) & $5 \mathrm{~nm}$ & (Background) \\
\hline
\end{tabular}

windows allow radiation to penetrate the whole atmosphere.

The dayside $0.90 \mu \mathrm{m}$ images visualize the distribution of clouds illuminated by sunlight. Although the dayside disk at this wavelength appears almost flat, small-scale features with contrasts of $\sim 3 \%$ are observed and considered to originate in the middle and lower cloud region (Belton et al., 1991). Tracking of such cloud features provides the wind field in this region.

On the nightside, IR1 measures the thermal radiation mostly from the surface and a little from the atmosphere. The $0.97 \mu \mathrm{m}$ radiation is partially absorbed by $\mathrm{H}_{2} \mathrm{O}$ vapor, and thus the comparison of this radiance with radiances at other wavelengths allows the estimation of $\mathrm{H}_{2} \mathrm{O}$ content below the cloud. Measurements at 0.90 and $1.01 \mu \mathrm{m}$ will yield information about the surface material (Baines et al.,
2000; Hashimoto and Sugita, 2003), and are expected to find out hot lava ejected from active volcanoes by utilizing the high sensitivity of the radiance to temperature in this wavelength region (Hashimoto and Imamura, 2001).

As imaging instruments, IR1 and IR2 have many common features. These cameras share electronics for A/D conversion since the detector arrays in these cameras are electronically nearly identical. Each of the cameras consists of a large baffle which eliminates stray light from the sun, refractive optics, a filter wheel, and a $1040 \times 1040$ pixels detector array $(1024 \times 1024$ area is used). The optics and the detector array altogether yield an effective FOV of $12^{\circ}$, giving the pixel resolution of $\sim 16 \mathrm{~km}$ from the apoapsis (13 Rv) and $\sim 6 \mathrm{~km}$ from the distance of $5 \mathrm{Rv}$. The detector array of IR1 is a Si-CSD (charge sweeping device)/CCD 
which is cooled down to $260 \mathrm{~K}$ to achieve a signal-to-noise ratio of $\sim 300$ on the dayside and $\sim 100$ on the nightside.

\section{$4.2 \quad 2-\mu \mathrm{m}$ Camera (IR2)}

IR2 utilizes the atmospheric windows at wavelengths of $1.73,2.26$, and $2.32 \mu \mathrm{m}$; the first two suffer only $\mathrm{CO}_{2}$ absorption, while the last one contains a $\mathrm{CO}$ absorption band. At these wavelengths the outgoing infrared radiation originates from the altitudes $35-50 \mathrm{~km}$.

To track cloud motions a series of $2.26 \mu \mathrm{m}$ images will be mostly used. As the small-scale inhomogeneity of the Venusian cloud layer is thought to occur predominantly at altitudes 50-55 km (Belton et al., 1991), the IR2 observations should yield wind maps in this region. As $\mathrm{CO}$ is photochemically produced above the cloud and subsequently transported to the deeper atmosphere (such sinks are not yet precisely located), the distribution of $\mathrm{CO}$ should give us information about the vertical circulation of the atmosphere. We will extract the CO distribution at $35-50 \mathrm{~km}$ altitudes by differentiating images taken at 2.26 and $2.32 \mu \mathrm{m}$ (Collard et al., 1993; Tsang et al., 2008). To study the spatial and temporal variations in the cloud particle size, the cloud opacities at 2.26 and $1.73 \mu \mathrm{m}$, together with the IR1 $1.01-\mu \mathrm{m}$ and $0.90-\mu \mathrm{m}$ images, will be analyzed with the aid of radiative transfer calculations (Carlson et al., 1993).

IR2 employs two additional wavelengths. At $2.02 \mu \mathrm{m}$, which is located in a prominent $\mathrm{CO}_{2}$ absorption band, we expect to observe the variation of the cloud-top altitude as intensity variations of the reflected sunlight similarly to the cloud altimetry by Venus Express VIRTIS using the 1.6- $\mu \mathrm{m}$ $\mathrm{CO}_{2}$ band (Titov et al., 2008). The astronomical H-band centered at $1.65 \mu \mathrm{m}$ aims at observing the zodiacal light.

IR2 utilizes a $1040 \times 1040$ pixels PtSi sensor $(1024 \times 1024$ area is used), which has advantages such as the high stability, uniformity and durability against energetic radiation. The architecture of the device is based on a technology of the $512 \times 512 \mathrm{PtSi}$ detector which was applied to astronomical observations (Ueno, 1996). To suppress the thermal electrons in the detector, it is cooled down to $65 \mathrm{~K}$ by a stirling cooler. Heat is also removed from the lens and lens housing, making these components be cooled down to $\sim 170 \mathrm{~K}$. The resultant signal-to-noise ratio is expected to be over 100 when imaging the Venusian nightside.

For observing the zodiacal light, the camera optics is designed to suppress the instrumental background as well as the stray light. The large baffle of the camera is very useful for IPD observations, because it provides us with very wide coverage in the solar elongation angle from $180^{\circ}$ (anti-solar direction) to $30^{\circ}$. The PtSi sensor is specially designed to realize precise measurements of the instrumental zero level. The stability of the zero level is essentially important for the IPD observations, because the target is extending beyond the instantaneous FOV of the camera.

\subsection{Ultraviolet Imager (UVI)}

The solar ultraviolet radiation scattered from the Venusian cloud top shows broad absorption between $200 \mathrm{~nm}$ and $500 \mathrm{~nm}$ wavelengths. $\mathrm{SO}_{2}$ explains the absorption between $200 \mathrm{~nm}$ and $320 \mathrm{~nm}$, while the absorber for $>320 \mathrm{~nm}$ has not yet been identified (Esposito et al., 1997). UVI is designed to map the ultraviolet contrast at $283 \mathrm{~nm}$ for observing $\mathrm{SO}_{2}$ and at $365 \mathrm{~nm}$ for the unknown absorber.
UVI will make clear the spatial distributions of these ultraviolet absorbers and their relationships with the cloud structure and the wind field. The tracking of ultraviolet markings yields wind vectors at the cloud top (Rossow et al., 1990). The mixing ratios of both $\mathrm{SO}_{2}$ and the unknown absorber are considered to increase precipitously with decreasing the altitude below the cloud top (Pollack et al., 1980; Bertaux et al., 1996), and thus the spatial distributions of these species should be sensitive to vertical air motions (Titov et al., 2008). In addition to nadir-viewing observations, limb observations will visualize the vertical structure of the haze layer above the main cloud (Belton et al., 1991).

UVI utilizes an ultraviolet-coated backthinned frame transfer Si-CCD with $1024 \times 1024$ pixels. Given the FOV of $12^{\circ}$, the pixel resolution is $\sim 16 \mathrm{~km}$ at the apoapsis (distance of $13 \mathrm{Rv}$ ) and $\sim 6 \mathrm{~km}$ from the distance of $5 \mathrm{Rv}$. The singal-to-noize ratio is expected to be $\sim 120$ when viewing the dayside Venus.

\subsection{Longwave Infrared Camera (LIR)}

LIR (Taguchi et al., 2007; Fukuhara et al., in press) detects thermal emission from the cloud top in a wavelength region $8-12 \mu \mathrm{m}$ to map the cloud-top temperature, which is typically $\sim 230 \mathrm{~K}$. Unlike other imagers onboard Akatsuki, LIR is able to take images of both dayside and nightside with equal quality. The cloud-top temperature map will reflect mostly the cloud height distribution, whose detailed structure is unknown except in the northern high latitudes observed by Pioneer Venus OIR (Taylor et al., 1980) and the southern high latitudes observed by Venus Express VIRTIS (Piccioni et al., 2007). LIR has a capability to resolve a temperature difference of $0.3 \mathrm{~K}$, corresponding to a few hundred-meters difference in the cloud height.

The images taken by LIR will visualize convective cells and various types of waves within the cloud layer. Tracking of the movements of blocky features will also yield wind vectors covering both dayside and nightside. Such a full local time coverage has never been achieved in the previous wind measurements, and will enable, for example, the derivation of zonal-mean meridional winds for the first time.

The sensor unit of LIR includes optics, a mechanical shutter, an image sensor and its drive circuit, and a baffle that keeps direct sunlight away from the optical aperture. The image sensor is an uncooled micro-bolometer array with $328 \times 248$ pixels for a FOV of $16.4^{\circ} \times 12.4^{\circ}$. Since the sensor can work under room temperature, huge and heavy cryogenic apparatus which is usually necessary for infrared devices is unnecessary. The frame rate of the image sensor is $60 \mathrm{~Hz}$, and several tens of images obtained within a few seconds will be accumulated to increase the signal-to-noise ratio. Given the FOV of $12.4^{\circ}$ for 248 pixels, the pixel resolution is $\sim 70 \mathrm{~km}$ on the Venus surface when viewed from the apoapsis ( $13 \mathrm{Rv}$ ), and is $\sim 26 \mathrm{~km}$ from the distance of $5 \mathrm{Rv}$.

\subsection{Digital Electronics unit (DE)}

DE is a controller for IR1, IR2, UVI and LIR. To conduct a set of camera operations which is repeated many times (every 2 hours in nominal global imaging), the main satellite system controller (Data Handling Unit) triggers the DE 
unit. DE, then, sequentially triggers detailed observation sequences of the cameras including filter wheel and gain settings, exposure, and data transfer. DE is also responsible for arithmetic data processing, data compression, and telemetry data formatting and packeting.

To repeat a variety of observation sequences (Section 5), each of which includes complicated manipulations of multiple cameras as a unit, we prepared a set of 'observation programs' and installed them in DE. For example, the 'day_delux' observation program setups the cameras, takes images using all dayside filters of the four cameras sequentially, conducts arithmetic data processing, compresses the acquired image data, and shutdowns the cameras, within 26 minutes. The observation programs will be updated several times during the mission depending on the results of the observations. The data compression ratios specified in the observation programs will also be changed during the mission depending on the Earth-Venus distance.

The arithmetic data processing includes dark signal subtraction, dead pixel correction, computation of median from multiple images, averaging of images, and flat field correction. The data compression method is either the lossless compression by the HIREW software developed by NEC Ltd. (Takada et al., 2007) or the JPEG2000 lossless/lossy compression (Boliek et al., 2000). Since the derivation of wind vectors from high-resolution cloud images might require high fidelity data acquisition, we will use lossless data compression as far as possible. However, in the epochs of low telemetry rate, lossy compression will also be adopted.

\subsection{Lightning and Airglow Camera (LAC)}

LAC (Takahashi et al., 2008) searches for lightning flashes and maps airglow emissions on the nightside disk of Venus when Akatsuki is located in the eclipse (umbra) of Venus. A major goal of the lightning observation is to settle the controversy on the occurrence of lightning in the Venusian atmosphere. The distribution of lightning, if it exists, should reflect the microphysics of clouds and the dynamics of mesoscale convection. The $777.4 \mathrm{~nm}$ [OI] line of atomic oxygen is utilized for lightning observation, since this line is considered as the most strong emission from lightning discharges according to a laboratory experiment simulating the Venusian atmosphere (Borucki et al., 1996). Possible lightning flashes were detected on the nightside disk of Venus at this wavelength by using a ground-based telescope (Hansell et al., 1995).

LAC also measures emissions in two airglow bands to study the global-scale circulation and small-scale waves in the lower thermosphere. One is the $\mathrm{O}_{2}$ Herzberg II emission centered at $552.5 \mathrm{~nm}$ wavelength, which is considered a consequence of the recombination of atomic oxygen in downwelling and is the strongest emission among the visible Venusian airglows (Slanger et al., 2001). The other is the $557.7 \mathrm{~nm}$ [OI] emission; though Venera 9 and 10 failed to detect this emission (Krasnopolsky, 1983), Slanger et al. (2001, 2006) observed it using a ground-based telescope.

LAC has a FOV of $16^{\circ}$. The detector is a multi-anode avalanche photo-diode (APD) with $8 \times 8$ pixels of $2 \mathrm{~mm}$ square each. Among the 64 pixels of the APD, $4 \times 8$ pixels are allocated to $777.4 \mathrm{~nm}$ for lightning detection, $2 \times 8$ pixels are allocated to $480-605 \mathrm{~nm}$ for $\mathrm{O}_{2}$ Herzberg II emission, $1 \times 8$ pixels are allocated to $557.7 \mathrm{~nm}$ emission, and $1 \times 8$ pixels are used for an airglow-free background at $545.0 \mathrm{~nm}$. These wavelengths are covered by using rectangular interference filters fixed on the detector.

In the lightning observation mode, individual lightning flashes are sampled at $32 \mathrm{kHz}$ by pre-triggering. Lightning flashes with an intensity of 1/100 of typical terrestrial lightning would be detected when viewed from $1000 \mathrm{~km}$ altitude. For mapping airglows, the Venusian nightside is scanned by changing the direction of the FOV. The detector's one pixel corresponds to $35 \mathrm{~km}$ resolution on the Venusian surface viewed from $1000 \mathrm{~km}$ altitude, and $850 \mathrm{~km}$ resolution from $3 \mathrm{Rv}$ altitude.

\subsection{Radio Science (RS)}

RS (Imamura et al., in press) aims to determine the vertical structure of the Venusian atmosphere using radio occultation technique. In this experiment, the spacecraft transmits radio waves toward the tracking station (Usuda Deep Space Center of Japan) and sequentially goes behind the planet's ionosphere, neutral atmosphere, and solid planet as seen from the tracking station, and reemerges in the reverse sequence. During such occultation events the neutral and ionized atmospheres of the planet cause bending, attenuation and scintillation of radio waves. The received signal is recorded with an open-loop system and analyzed offline.

The frequency variation observed at the tracking station yields the time series of the bending angle, from which the vertical profile of the refractive index is derived. The refractive index profile yields the temperature profile of the neutral atmosphere by assuming hydrostatic balance (Fjeldbo et al., 1971). The height range of the Venusian neutral atmosphere accessible by radio occultation is approximately 32-90 km; below $32 \mathrm{~km}$ the radius of curvature of the ray path becomes smaller than the distance to the planet center. The ionospheric electron density profile is also derived from the refractive index profile. From the observed signal power variation, the sub-cloud $\mathrm{H}_{2} \mathrm{SO}_{4}$ vapor densities (Jenkins et al., 1994) and the intensity of small-scale density fluctuation (Woo et al., 1980) are obtained.

The uniqueness of Akatsuki RS as compared to the previous radio occultation experiments at Venus is that low latitudes can be probed many times thanks to the nearequatorial orbit, so that broad local time regions are covered. Another merit of Akatsuki is that the locations probed by RS can be observed by the cameras a short time before or after the occultations.

An ultra-stable oscillator (USO) provides a stable reference frequency which is needed to generate the $\mathrm{X}$-band downlink signal used for RS. The USO is a heritage from the USOs flown onboard the ESA's Rosetta and Venus Express spacecraft (Häusler et al., 2006).

\section{Observation Modes}

Given a variety of scientific interest described in Section 2, the optimal observation mode changes as the geometrical relationship among Akatsuki, Venus, the Earth and the sun changes. The observation modes we have prepared are roughly classified into the following six groups. These observations are conducted sequentially in each orbital revolution. 


\subsection{Global imaging}

Global imaging will be done using IR1, IR2, UVI and LIR in the portion of the orbit where the typical camera FOV of $12^{\circ}$ roughly covers the apparent Venus disk; this portion corresponds approximately to 20 hours centered at the apoapsis (Fig. 3). Cloud images will be obtained every 2 hours (nominal) for each observation wavelength from this 'quasi-synchronized' part of the orbit. By using these successive images, the development of the atmospheric structure is monitored, and wind vectors are derived by tracking small-scale cloud features with crosscorrelation method (Rossow et al., 1990). Once the spacecraft passes through the periapsis and returns to the apoapsis side again, the cloud-level air mass that was observed in the previous apoapsis passage has advected westward by 60 $100^{\circ}$ in longitude depending on the observed altitude in the cloud layer. Therefore, a $360^{\circ}$ zonal overage of the cloud layer needs 4-6 orbital revolutions.

The camera pointing direction for this observation is not always nadir, but shifted to the sunlit side for dayside imaging and to the dark side for nightside imaging by up to $\sim 10^{\circ}$. The purposes of this angular offset are (1) to include the planetary limb in the image so that the pointing direction can be determined accurately from the limb position, (2) to maximize the area of the atmosphere or the surface observable with each filter, and (3) to avoid stray light when observing the nightside. When both dayside surface and nightside surface are visible with more than $30 \%$ of the disk area from the spacecraft, dayside observations and nightside observations are sequentially conducted with an attitude maneuver between them.

It should be noted that the orbital phase which is allocated to the data downlink to the tracking station changes from revolution to revolution because the orbital period is not 24 hours. To minimize the interruption of the global imaging, interruptions of data transfer will be considered when the telecommunication window overlaps the orbital phase suitable for global imaging.

\subsection{Close-up imaging}

In the close-up imaging mode, a particular point on the cloud layer is continuously monitored using principally UVI and LIR from the distances of roughly 1000$10000 \mathrm{~km}$, for the purpose of observing the temporal development of meso-scale processes and also for stereo-viewing of the cloud tops. During this observation sequence, cloud images are obtained every 5-10 minutes, while the spacecraft attitude is controlled so that the camera FOV continuously capture roughly the same region. This observation mode basically targets dayside clouds, which should show extremely fine structures when viewed from up close (Markiewicz et al., 2007).

\subsection{Limb imaging}

The vertical distribution of aerosols which extend up to $\sim 100 \mathrm{~km}$ altitude is observed in limb-viewing geometry around a dayside periapsis passage using UVI, IR1 $(0.90 \mu \mathrm{m})$ and LIR. The cameras will be directed to the tangential height of $\sim 85 \mathrm{~km}$, where the line-of-sight optical depth is around unity (Belton et al., 1991). When the periapsis altitude is $400 \mathrm{~km}$, the minimum distance to the tangential point is $2000 \mathrm{~km}$, giving a vertical resolution of
$400 \mathrm{~m}$.

\subsection{Zonal scan}

Strips of, or intermittent cloud maps along the orbital tracks on the periapsis side are obtained by successive nadir observations using IR1, IR2, UVI and LIR. The cameras are operated for 1-2 hours around the periapsis with imaging intervals of shorter than 10 minutes. Although the instantaneous FOV is less than $\sim 1000 \mathrm{~km}$ on Venus and only the low latitude is covered, a set of such close-up images can capture a quasi-one dimensional zonal profile of the atmosphere, which should complement the global images taken from the apoapsis side in the studies of global-scale dynamics.

\subsection{Eclipse observation}

The eclipse (umbra) region along the orbit is allocated to LAC for observing lightning and airglow. Eclipses occur mostly near the periapsis with a typical duration of several tens of minutes. In the lightning search mode, LAC is operated in nadir-pointing geometry and waits for lightning flashes with event trigger method. In the airglow observation mode, LAC continuously records brightnesses while scanning the nightside disk by the attitude maneuver or the orbital motion of the spacecraft. Lightning search and airglow measurements cannot be conducted simultaneously.

Nadir observations by IR2 and LIR will also be conducted together with the lightning observations depending on the condition of the onboard batteries. These data will be utilized to locate lightning flashes in particular meteorological events. Observations of lightning using UVI will also be tried with a long exposure time; although the sensitivity and temporal resolution of UVI are far below those of LAC, the high spatial resolution of UVI might complement LAC in lightning observations.

\subsection{Radio occultation}

Radio occultation experiments (RS) are performed when the spacecraft is hidden by Venus as viewed from the tracking station. Since the dense Venusian atmosphere causes considerable ray bending exceeding several tens of degrees, a spacecraft steering is required to compensate for this effect while the occultation geometry changes from ingress occultation to egress occultation. Without spacecraft steering, the radio waves, which are emitted from the high gain antenna within a $3-\mathrm{dB}$ attenuation width of $\sim 1^{\circ}$, would miss the Earth. The duration allocated to RS covering both ingress and egress is 1-2 hours for each revolution. The location probed by RS will be imaged by IR1, IR2, UVI and LIR a short time ( $<1$ hour) before the ingress or short time after the egress.

\section{Data Processing}

The observational data which will be archived for public release are classified into level-2 and level-3. The level-2 data include calibrated images with geometrical information and vertical profiles from RS. The level-3 data include higher-level products. The data processing for these products is pipelined so that the products are released without long delay after data acquisition.

\subsection{Level-2 products}

Each image data will be stored in a file in the Flexible Image Transport System (FITS) format, which is com- 
posed of an image data block and a header block. The data block contains radiances or brightness temperatures for all pixels, which were converted from raw counts based on a calibration table. The header block contains ancillary information such as the time of the exposure, the filter selection, the instrument status, the geometry of observation, and the orbital information. In addition to these FITS image files, we will prepare an additional FITS file for each image, which contains the latitudes, the longitudes, the incident angles, the emission angles, the phase angles, the azimuth angles between the incident and emission rays, and the local solar times for all points where the line of sights for the camera pixels intersect with reference altitude surfaces of the Venusian atmosphere. These level-2 products will be archived in the Planetary Data System (PDS) or a system similar to PDS.

\subsection{Level-3 products}

Images of Venus projected onto regular longitudelatitude grids will be archived as a part of the level-3 products. The data format is the Network Common Data Form (NetCDF), which is commonly used among meteorologists. These grid data become the input data for the cloud tracking described later.

Before the projection onto longitude-latitude grids, the camera pointing direction is redetermined from the position of Venus in each image. This is because the accuracy of the onboard attitude determination is not enough for cloud tracking (Section 3). In the pipeline the position of the center of Venus in each image is determined by fitting an arc to the observed limb with the radius of the arc also being an unknown parameter. The limb of Venus is defined as the position where the spatial differentiation of the radiance with respect to each horizontal line has the largest absolute value.

In the final stage of the data stream, horizontal distributions of the zonal wind and the meridional wind are obtained by tracking cloud features found in the Venus images taken by cameras except LAC in the longitude-latitude coordinate. Considering that different wavelength filters correspond to different altitudes, a three-dimensional distribution of the horizontal wind is obtained by combining the cloud tracked winds from different wavelength images. For tracking small-scale cloud features, the global-scale brightness variation due to spherical geometry is removed and a high pass filter is applied before analysis. In the pipeline the cross correlation method (e.g., Rossow et al., 1990) will be used for deriving cloud motions using a pair of cloud images; when the displacement of a template area from the first image to the second image, which are separated by a time increment of $\Delta t$, is determined by finding the correlation maximum, the division of the displacement vector by $\Delta t$ gives the velocity vector. This velocity will be approximately equals to the wind velocity when tracking small-scale clouds which are considered passive tracers. The zonal and meridional winds are obtained at regular longitude-latitude grids in the pipeline and will be archived as a level-3 product in the NetCDF format together with the gridded image data. The source code of the cloud tracking program will also be released to the public so that users can perform cloud tracking by themselves with different values of adjustable parameters using the level-3 Venus images.

\section{Relationship with Venus Express}

The science of Akatsuki is strongly related to that of ESA's Venus Express, which was inserted into a Venusian orbit in 2006 (Svedhem et al., 2007). Since the mission periods were expected to overlap each other, coordinated observation plans using Akatsuki and Venus Express were developed. Venus Express' science objectives are to study the atmosphere, the plasma environment, and the surface of Venus. The science payload consists of three spectrometers, an imager, a plasma analyzer, a magnetometer and an USO. The orbit of Venus Express has an apoapsis over the south pole, enabling global imaging of the southern hemisphere and close-up observation of the northern hemisphere and the equatorial region.

Regarding atmospheric observations, the striking difference between Akatsuki and Venus Express is that the former focuses on dynamics with imaging observations from an equatorial orbit, while the latter covers broad topics including chemistry and dynamics with sophisticated spectroscopic observations from a polar orbit, although two instruments (VMC and VIRTIS) on Venus Express have imaging capability. The two missions are complementary each other not only in the science objectives but also in the spatial and temporal coverage.

The way of surface observation utilizing the near-infrared windows is also different between Akatsuki and Venus Express. IR1 on Akatsuki maps the surface globally and continuously, together with the overlying clouds, at $0.90 \mu \mathrm{m}$ and $1.01 \mu \mathrm{m}$ wavelengths. Such observations allow us to discriminate surface features from cloud features rather easily since clouds move and change their shapes with time. Venus Express, having more wavelength bands for surface observation, yields better spectroscopic data on the surface material.

\section{Concluding Remarks}

The aim of the Japan's Venus probe Akatsuki is to understand the mechanism of the Venus' atmospheric dynamics and cloud formation, with secondary targets being the exploration of the ground surface and the zodiacal light observation during the cruise to Venus. The three-dimensional structure of the atmosphere and its dynamics will be studied with the combination of five multi-wavelength cameras and radio occultation. The atmosphere below the cloud top is probed by two near-infrared cameras by utilizing the nearinfrared windows. The cloud top is covered by an ultraviolet camera and an infrared camera. Lightning flashes and night airglows are also observed by a dedicated sensor.

With these instruments dedicated to meteorological study, we are planning a systematic observation sequence to detect dynamical processes with various temporal and spatial scales. The elliptical, near-equatorial orbit is suitable for obtaining successive global images to derive cloudtracked wind vectors. Using such wind data, together with cloud and minor gas maps, the meridional circulation, midlatitude jets and various wave activities which might ultimately cause the super-rotation will be studied. Close-up and limb observations will also be conducted near the peri- 
apsis for a detailed look at small-scale structures. It should be noted that the observation strategies described here cannot be realized with ground-based telescopes, which have severe limitations on continuous sampling, spatial resolution and simultaneous multi-band observations. A dedicated Venus orbiter is essential to the study of Venus meteorology.

The Venus orbit insertion maneuver for Akatsuki on December 7, 2010 has failed. At present the spacecraft is orbiting the Sun, and it will have a chance to encounter Venus 5 or 6 years later. JAXA is examining the possibility of conducting an orbit insertion maneuver again at this opportunity.

Acknowledgments. We would like to acknowledge all members of the PLANET-C project team for developing the mission plan, the spacecraft and the science instruments. The instruments could not have been developed without the tremendous effort made by NEC TOSHIBA Space Systems, Ltd., Sumitomo Heavy Industries, Ltd., Mitsubishi Electric Co., Ltd., Nikon Co., Ltd., Meisei Electric Co., Ltd., and Magoshi Co., Ltd. We are also grateful to the Venus Express project team for a fruitful collaboration and providing valuable advices. The paper has been improved by constructive suggestions made by the reviewers F. Taylor and $\mathrm{S}$. Sasaki.

\section{References}

Allen, D., D. Crisp, and V. Meadows, Variable oxygen airglow on Venus as a probe of atmospheric dynamics, Nature, 359, 516-519, 1992.

Baines, K. H. et al., Detection of sub-micron radiation from the surface of Venus by Cassini/VIMS, Icarus, 148, 307-311, 2000.

Baker, R. D. and G. Schubert, Cellular convection in the atmosphere of Venus, Nature, 355, 710-712, 1992.

Basilevsky, A. T., J. W. Head, G. G. Schaber, and R. G. Strom, The resurfacing history of Venus, in Venus II, edited by S. W. Bougher, D. M. Hunten, and R. J. Phillips, 1047-1084, Univ of Arizona Press, Tucson, 1997.

Belton, M. J. S., P. J. Gierasch, M. D. Smith, P. Helfenstein, P. J. Schinder, J. B. Pollack, K. A. Rages, A. P. Ingersoll, K. P. Klaasen, J. Veverka, C. D. Anger, M. H. Carr, C. R. Chapman, M. E. Davies, F. P. Fanale, R. Greeley, R. Greenberg, J. W. Head III, D. Morrison, G. Neukum, and C. B. Pilcher, Imaging from Galileo of the Venus cloud deck, Science, 253, 1531-1536, 1991.

Bertaux, J.-L., T. Widemann, A. Hauchecorne, V. I. Moroz, and A. P. Ekonomov, VEGA 1 and VEGA 2 entry probes: An investigation of local UV absorption (220-400 nm) in the atmosphere of Venus $\left(\mathrm{SO}_{2}\right.$ aerosols, cloud structure), J. Geophys. Res., 101, 12709-12745, 1996.

Boliek, M., C. Christopoulos, and E. Majani, eds., JPEG 2000 Part I Final Committee Draft Version 1.0, ISO/IEC JTC1/SC29/WG1, N1646R, 2000.

Borucki, W. J., C. P. McKay, D. Jebens, H. S. Lakkaraju, and C. T. Vanajakshi, Spectral irradiance measurements of simulated lightning in planetary atmospheres, Icarus, 123, 336-344, 1996.

Bougher, S. W., M. J. Alexander, and H. G. Mayr, Upper atmosphere dynamics: global circulation and gravity waves, in Venus II, edited by S. W. Bougher, D. M. Hunten, and R. J. Phillips, 259-292, Univ of Arizona Press, Tucson, 1997.

Carlson, R. W., L. W. Kamp, K. H. Baines, J. B. Pollack, D. H. Grinspoon, Th. Encrenaz, P. Drossart, and F. W. Taylor, Variations in Venus cloud particle properties: a new view of Venus's cloud morphology as observed by the Galileo near-infrared mapping spectrometer, Planet. Space Sci., 41, 477-485, 1993.

Colin, L., The Pioneer Venus Program, J. Geophys. Res., 85, 7575-7598, 1980.

Collard, A. D., F. W. Taylor, S. B. Calcutt, R. W. Carlson, L. W. Kamp, K. H. Baines, Th. Encrenaz, P. Drossart, E. Lellouch, and B. Bézard, Latitudinal distribution of carbon monoxide in the deep atmosphere of Venus, Planet. Space Sci., 41, 487-494, 1993.

Covey, C. and G. Schubert, Planetary-scale waves in the Venus atmosphere, J. Atmos. Sci., 39, 2397-2413, 1982.

Crisp, D., Radiative forcing of the Venus mesosphere II. Thermal fluxes, cooling rates, and radiative equilibrium temperatures, Icarus, 77, 391413, 1989.

Crisp, D., V. S. Meadows, B. Bezard, C. de Bergh, J. -P. Maillard, and F. P. Mills, Ground-based near-infrared observations of the Venus nightside: $1.27-\mu \mathrm{m} \mathrm{O}_{2}\left(\mathrm{a}^{1} \Delta_{\mathrm{g}}\right)$ airglow from the upper atmosphere, J. Geophys. Res., 101, 4577-4593, 1996.

Del Genio, A. D. and W. B. Rossow, Planetary-scale waves and the cyclic nature of cloud top dynamics on Venus, J. Atmos. Sci., 47, 293-318, 1990.

Del Genio, A. D. and W. Zhou, Simulations of superrotation on slowly rotating planets: Sensitivity to rotation and initial condition, Icarus, 120, 332-343, 1996.

Dermott, S. F., P. D. Nicholson, J. A. Burns, and J. R. Houck, Origin of the solar system dust bands discovered by IRAS, Nature, 312, 505-509, 1984.

Ekonomov, A. P., V. I. Moroz, B. E. Moshkin, V. I. Gnedykh, Yu. M. Golovin, and A. V. Crigoryev, Scattered UV solar radiation within the clouds of Venus, Nature, 1307, 345-347, doi:10.1038/307345a0, 1984.

Elson, L. S., Wave instability in the polar region of Venus, J. Atmos. Sci., 39, 2356-2362, 1982.

Esposito, L. W., R. G. Knollenberg, M. Y. Marov, O. B. Toon, and R. P. Turco, The clouds and hazes of Venus, in Venus, edited by D. M. Hunten, L. Colin, T. M. Donahue, and V. I. Moroz, University of Arizona Press, 1983.

Esposito, L. W., J. L. Bertaux, V. Krasnopolsky, V. I. Moroz, and L. V. Zasova, Chemistry of lower atmosphere and clouds, in Venus II, edited by S. Bougher, D. Hunten, and R. Phillips, University of Arizona Press., 1997.

Fegley, Jr., B., G. Klingelhofer, K. Lodders, and T, Widemann, in Venus II, edited by S. Bougher, D. Hunten, and R. Phillips, University of Arizona Press, 1997.

Fels, S. and R. S. Lindzen, Interaction of thermally excited gravity waves with mean flows, Geophys. Fl. Dyn., 6, 149-191, 1974.

Fjeldbo, G., A. J. Kliore, and V. R. Eshleman, The neutral atmosphere of Venus as studied with the Mariner V radio occultation experiments, Astron. J., 76, 123-140, 1971.

Fukuhara, T., M. Taguchi, T. Imamura, M. Nakamura, M. Ueno, M. Suzuki, N. Iwagami, M. Sato, K. Mitsuyama, G. L. Hashimoto, R. Ohshima, T. Kouyama, H. Ando, and M. Futaguchi, LIR: Longwave Infrared Camera onboard the Venus orbiter Akatsuki, Earth Planets Space, 2011 (in press).

Gierasch, P. J., Meridional circulation and the maintenance of the Venus atmospheric rotation, J. Atmos. Sci., 32, 1,038-1,044, 1975.

Gierasch, P. J. et al., The general circulation of the Venus atmosphere: An assessment, in Venus II, edited by S. Bougher, D. Hunten, and R. Phillips, pp. 459-500, University of Arizona Press, Tucson, 1997.

Grebowsky, J. M., R. J. Strangeway, and D. M. Hunten, Evidence for Venus lightning, in Venus II, edited by S. Bougher, D. Hunten, and R. Phillips, University of Arizona Press, Tucson, 1997.

Hansell, S. A., W. K. Wells, and D. M. Hunten, Optical detection of lightning on Venus, Icarus, 117, 345-351, 1995.

Hashimoto, G. L. and Y. Abe, Stabilization of Venus' climate by a chemical-albedo feedback, Earth Planets Space, 52, 197-202, 2000.

Hashimoto, G. L. and Y. Abe, Climate control on Venus: comparison of the carbonate and pyrite models, Planet. Space Sci., 53, 839-848, 2005.

Hashimoto, G. L. and T. Imamura, Elucidating the rate of volcanism on Venus: Detection of lava eruptions using near-infrared observations, Icarus, 154, 239-243, 2001.

Hashimoto, G. L. and S. Sugita, On observing the compositional variability of the surface of Venus using nightside near-infrared thermal radiation, J. Geophys. Res., 108, 5109, doi:10.1029/2003JE002082, 2003.

Hashimoto, G. L., M. Roos-Serote, S. Sugita, M. S. Gilmore, L. W. Kamp, R. W. Carlson, and K. H. Baines, Felsic highland crust on Venus suggested by Galileo Near-Infrared Mapping Spectrometer data, J. Geophys. Res., 113, E00B24, doi:10.1029/2008JE003134, 2008.

Häusler, B., M. PŁtzold, G. L. Tyler, R. A. Simpson, M. K. Bird, V. Dehant, J.-P. Barriot, W. Eidel, R. Mattei, S. Remus, J. Selle, S. Tellmann, and T. Imamura, Radio science investigations by VeRa onboard the Venus Express spacecraft, Planet. Space Sci, 54, 1315-1335, 2006.

Hinson, D. P. and J. M. Jenkins, Magellan radio occultation measurements of atmospheric waves on Venus, Icarus, 114, 310-327, 1995.

Hollingsworth, J. L., R. E. Young, G. Schubert, C. Covey, and A. S. Grossman, A simple-physics global circulation model for Venus: Sensitivity assessments of atmospheric superrotation, Geophys. Res. Lett., 34, L05202, doi:10.1029/2006GL028567, 2007.

Hou, A. Y. and R. M. Goody, Further studies of the circulation of the Venus 
atmosphere, J. Atmos. Sci., 46, 991-1001, 1989.

Iga, S. and Y. Matsuda, Shear instability in a shallow water model with implication for the Venus atmosphere, J. Atmos. Sci., 62, 2514-2527, 2005.

Imamura, T., Momentum balance of the Venusian midlatitude mesosphere, J. Geophys. Res., 102, 6615-6620, 1997.

Imamura, T. and G. L. Hashimoto, Venus cloud formation in the meridional circulation, J. Geophys. Res., 103, 31349-31366, 1998.

Imamura, T. and G. L. Hashimoto, Microphysics of Venusian clouds in rising tropical air, J. Atmos. Sci., 58, 3597-3612, 2001.

Imamura, T., T. Toda, A. Tomiki, D. Hirahara, T. Hayashiyama, N. Mochizuki, Z.-i. Yamamoto, T. Abe, T. Iwata, H. Noda, Y. Futaana, H. Ando, B. Häusler, M. Pätzold, and A. Nabatov, Radio occultation experiment of the Venus atmosphere and ionosphere with the Venus orbiter Akatsuki, Earth Planets Space, 2011 (in press).

Ishiguro, M., M. Ueno, F. Usui, R. Nakamura, T. Mukai, S. M. Kwon, A. Miyashita, K. Sekiguchi, and M. Nakagiri, Development of zodiacal light observation system: WIZARD, SPIE, 4842, 366-374, 2002.

Ishii, N., H. Yamakawa, S. Sawai, M. Shida, T. Hashimoto, M. Nakamura, T. Imamura, T. Abe, K.-I. Oyama, and I. Nakatani, Current status of the PLANET-C Venus orbiter design, Adv. Space Res., 34, 1668-1672, 2004

Iwagami, N., S. Takagi, S. Ohtsuki, M. Ueno, K. Uemizu, T. Satoh, T. Sakanoi, and G. L. Hashimoto, Science requirements and description of the $1 \mu \mathrm{m}$ camera onboard the Akatsuki Venus Orbiter, Earth Planets Space, 2011 (in press).

Jenkins, J. M., P. G. Steffes, D. P. Hinson, J. D. Twicken, and G. L. Tyler, Radio occultation studies of the Venus atmosphere with the Magellan spacecraft: 2. Results from the October 1991 experiments, Icarus, 110, 79-94, 1994.

Johnson, T. V., C. M. Yeates, R. Young, and J. Dunne, The Galileo Venus encounter, Science, 253, 1516-1518, 1991.

Kelsall, T., J. L. Weiland, B. A. Franz, W. T. Reach, R. G. Arendt, E. Dwek, H. T. Freudenreich, M. G. Hauser, S. H. Moseley, N. P. Odegard, R. F. Silverberg, and E. L. Wright, The COBE diffuse infrared background experiment search for the cosmic infrared background. II. Model of the interplanetary dust cloud, Astrophys. J., 508, 44-73, 1998.

Kido, A. and Y. Wakata, Multiple equilibrium states appearing in a Venuslike atmospheric general circulation model, J. Meteor. Soc. Jpn., 86, 969-979, 2008.

Kliore, A. J., Radio occultation observations of the ionospheres of Mars and Venus, AGU Geophysical Monograph Series, 66, 265-276, 1992.

Knollenberg, R. G. and D. M. Hunten, The microphysics of the clouds of Venus: results of the Pioneer Venus particle size spectrometer experiment, J. Geophys. Res., 85, 8039-8058, 1980

Krasnopolsky, V. A., Venus spectroscopy in the 3000-8000 $\AA$ region by Veneras 9 and 10, in Venus, edited by D. M. Hunten, L. Colin, T. M. Donahue, and V. I. Moroz, University of Arizona Press, 1983.

Krasnopolsky, V. A. and J. B. Pollack, $\mathrm{H}_{2} \mathrm{O}-\mathrm{H}_{2} \mathrm{SO}_{4}$ system in Venus' clouds and $\mathrm{OCS}, \mathrm{CO}$, and $\mathrm{H}_{2} \mathrm{SO}_{4}$ profiles in Venus' troposphere, Icarus, 109, 58-78, 1994.

Lee, C., S. R. Lewis, and P. L. Read, Superrotation in a Venus general circulation model, J. Geophys. Res., 112, E04S11, doi:10. 1029/2006JE002874, 2007

Leroy, S. S. and A. P. Ingersoll, Radio scintillations in Venus's atmosphere: application of a theory of gravity wave generation, J. Atmos. Sci., 53, 1018-1028, 1996.

Limaye, S. S. and V. E. Suomi, Cloud motions on Venus: global structure and organization, J. Atmos. Sci., 38, 1220-1235, 1981.

Limaye, S. S., C. Grassotti, and M. J. Kuetemeyer, Venus: Cloud level circulation during 1982 as determined from pioneer cloud photopolarimeter images I. Time and zonally averaged circulation, Icarus, 73, 193$211,1988$.

Markiewicz, W. J., D. V. Titov, S. S. Limaye, H. U. Keller, N. Ignatiev, R. Jaumann, N. Thomas, H. Michalik, R. Moissl, and P. Russo, Morphology and dynamics of the upper cloud layer of Venus, Nature, 450, doi:10.1038/nature06320, 2007.

McGouldrick, K. and O. B. Toon, An investigation of possible causes of the holes in the condensational Venus cloud using a microphysical cloud model with a radiative-dynamical feedback, Icarus, 191, 1-24, 2007.

Moissl, R., I. Khatuntsev, S. S. Limaye, D. V. Titov, W. J. Markiewicz, N. I. Ignatiev, T. Roatsch, K.-D. Matz, R. Jaumann, M. Almeida, G. Portyankina, T. Behnke, and S. F. Hviid, Venus cloud top winds from tracking UV features in Venus Monitoring Camera images, J. Geophys. Res., 114, E00B31, doi:10.1029/2008JE003117, 2009.

Moroz, V. I., Summary of preliminary results of the Venera 13 and Venera
14 missions, in Venus, edited by D. M. Hunten, L. Colin, T. M. Donahue, and V. I. Moroz, 45-68, University of Arizona Press, 1983.

Newman, M. and C. B. Leovy, Maintenance of strong rotational winds in Venus? middle atmosphere by thermal tides, Science, 257, 647-650, 1992.

Newman, M., G. Schubert, A. J. Kliore, and I. R. Patel, Zonal winds in the middle atmosphere of Venus from Pioneer Venus radio occultation data, J. Atmos. Sci., 41, 1901-1913, 1984.

Ohtsuki, S., N. Iwagami, H. Sagawa, M. Ueno, Y. Kasaba, T. Imamura, K. Yanagisawa, and E. Nishihara, Distributions of the Venus $1.27-\mu \mathrm{m} \mathrm{O}_{2}$ airglow and rotational temperature, Planet. Space Sci., 56, 1391-1398, 2008.

Pätzold, M., B. Häusler, M. K. Bird, S. Tellmann, R. Mattei, S. W. Asmar, V. Dehant, W. Eidel, T. Imamura, R. A. Simpson, and G. L. Tyler, The structure of Venus' middle atmosphere and ionosphere, Nature, 450, 657-660, 2007.

Peralta, J., R. Hueso, A. Sánchez-Lavega, G. Piccioni, O. Lanciano, and P. Drossart, Characterization of mesoscale gravity waves in the upper and lower clouds of Venus from VEX-VIRTIS images, J. Geophys. Res. 113, E00B18, doi:10.1029/2008JE003185, 2008.

Piccioni, G. et al., South-polar features on Venus similar to those near the north pole, Nature, 450, doi:10.1038/nature06209, 2007.

Pollack, J. B., O. B. Toon, R. C. Whitten, R. Boese, B. Ragent, M. Tomasko, L. Esposito, L. Travis, and D. Wiedman, Distribution and source of the UV absorption in Venus' atmosphere, J. Geophys. Res., $\mathbf{8 5}, 8141-8150,1980$.

Rossow, W. B. and G. P. Williams, Large-scale motion in the Venus stratosphere, J. Atmos. Sci., 36, 377-389, 1979.

Rossow, W. B., A. D. Del Genio, S. S. Limaye, and L. D. Travis, Cloud morphology and motions from Pioneer Venus images, J. Geophys. Res., 85, 8107-8128, 1980.

Rossow, W. B., A. D. Del Genio, and T. Eichler, Cloud-tracked winds from Pioneer Venus OCPP images, J. Geophys. Res., 47, 2053-2084, 1990.

Russell, C. T., T. L. Zhang, M. Delva, W. Magnes, R. J. Strangeway, and H. Y. Wei, Lightning on Venus inferred from whistler-mode waves in the ionosphere, Nature, 450, 661-662, doi:10.1038/nature05930, 2007.

Sagdeev, R. Z., V. M. Linkin, V. V. Kerzhanovich, A. N. Lipatov, A. A Shurupov, J. E. Blamont, D. Crisp, A. P. Ingersoll, L. S. Elson, R. A. Preston, C. E. Hildebrand, B. Ragent, A. Seiff, R. E. Young, G. Petit, L. Boloh, Yu. N. Alexandrov, N. A. Armand, R. V. Bakitko, and A. S. Selivanov, Overview of VEGA Venus balloon in situ meteorological measurements, Science, 231, 1411-1414, 1986.

Sánchez-Lavega, A., R. Hueso, G. Piccioni, P. Drossart, J. Peralta, S Pérez-Hoyos, C. F. Wilson, F. W. Taylor, K. H. Baines, D. Luz, S. Erard, and S. Lebonnois, Variable winds on Venus mapped in three dimensions, Geophys. Res. Lett., 35, L13204, doi:10.1029/2008GL033817, 2008.

Saunders, R. S. et al., Magellan mission summary, J. Geophys. Res., 97, 13067-13090, 1992.

Schaefer, L. and B. Fegley Jr., Heavy metal frost on Venus, Icarus, 168 , 215-219, 2004.

Schubert, G., C. Covey, A. Del Genio, L. S. Elson, G. Keating, A. Seiff, R. E. Young, J. Apt, C . C. Counselman III, A. J. Kliore, S. S. Limaye, H. E. Revercomb, L. A. Sromovsky, V. E. Suomi, F. Taylor, R. Woo, and U. von Zahn, Structure and circulation of the Venus atmosphere, $J$. Geophys. Res., 85, 8007-8025, 1980.

Schubert, G., General circulation and dynamical state of the Venus atmosphere, in Venus, edited by D. M. Hunten, L. Colin, T. M. Donahue, and V. I. Moroz, University of Arizona Press, 1983.

Seiff, A., Dynamical implications of the observed thermal contrasts in Venus' upper atmosphere, Icarus, 51, 574-592, 1982.

Slanger, T. G., P. C. Cosby, D. L. Huestis, and T. A. Bida, Discovery of the atomic oxygen green line in the Venus night airglow, Science, 291, 463-465, 2001.

Slanger, T. G., D. L. Huestis, P. C. Cosby, N. J. Chanover, and T. A Bida, The Venus nightglow: Ground-based observations and chemical mechanisms, Icarus, 182, 1-9, 2006.

Smith, M. D., P. J. Gierasch, and P. J. Schinder, Global-scale waves in the Venus atmosphere, J. Atmos. Sci., 50, 4080-4096, 1993.

Stone, P. H., The structure and circulation of the deep Venus atmosphere, J. Atmos. Sci., 31, 1681-1690, 1974.

Svedhem, H., D. V. Titov, D. McCoy, J.-P. Lebreton, S. Barabash, J.L. Bertaux, P. Drossart, V. Formisano, B. Häusler, O. Korablev, W. J. Markiewicz, D. Nevejans, M. Pätzold, G. Piccioni, T. L. Zhang, F. W. Taylor, E. Lellouch, D. Koschny, O. Witasse, H. Eggel, M. Warhaut, A. Accomazzo, J. Rodriguez-Canabal, J. Fabrega, T. Schirmann, A. Clochet, and M. Coradini, Venus Express-The first European mission 
to Venus, Planet. Space Sci., 55, 1636-1652, 2007.

Sykes, M. V. and R. Greenberg, The formation and origin of the IRAS zodiacal dust bands as a consequence of single collisions between asteroids, Icarus, 65, 51-69, 1986.

Sykes, M. V. and R. G. Walker, Cometary dust trails. I-Survey, Icarus, 95, 180-210, 1992.

Taguchi, M., T. Fukuhara, T. Imamura, M. Nakamura, N. Iwagami, M. Ueno, M. Suzuki, G. L. Hashimoto, and K. Mitsuyama, Longwave infrared camera onboard the Venus Climate Orbiter, Adv. Space Res., 40, 861-868, 2007.

Takada, J., S. Senda, H. Hihara, M. Hamai, T. Oshima, S. Hagino, M. Suzuki, and S. Ichikawa, A fast progressive lossless image compression method for space and satellite images, Geoscience and Remote Sensing Symposium, IGARSS 2007, IEEE International, 479-481, 10.1109/IGARSS.2007.4422835, 2007.

Takagi, M. and Y. Matsuda, Sensitivity of thermal tides in the Venus atmosphere to basic zonal flow and Newtonian cooling, Geophys. Res. Lett., 32, 10.1029/2004GL022060, 2005.

Takagi, M. and Y. Matsuda, Effects of thermal tides on the Venus atmospheric superrotation, J. Geophys. Res., 112, D09112, doi:10. 1029/2006JD007901, 2007.

Takagi, S. and N. Iwagami, Contrast sources for the infrared images taken by the Venus mission AKATSUKI, Earth Planets Space, 63, this issue, 435-442, 2011

Takahashi, Y., J. Yoshida, Y. Yair, T. Imamura, and M. Nakamura, Lightning detection by LAC onboard the Japanese Venus Climate Orbiter, Planet-C, Space Sci. Rev., 137, 317-334, doi:10.1007/s11214-0089400-x, 2008.

Taylor, F. W. et al., Structure and meteorology of the middle atmosphere of Venus: infrared remote sounding from the Pioneer Orbiter, J. Geophys. Res., 85, 7963-8006, 1980.

Taylor, F. W., D. Crisp, and B. Bezard, Near-infrared soudings of the lower atmosphere of Venus, in Venus II, edited by S. Bougher, D. Hunten, and R. Phillips, University of Arizona Press, 1997.

Tellmann, S., M. Pätzold, B. Häusler, M. K. Bird, and G. L. Tyler, Structure of the Venus neutral atmosphere as observed by the Radio Science experiment VeRa on Venus Express, J. Geophys. Res., 114, E00B36, doi:10.1029/2008JE003204, 2009.

Titov, D. V., F. W. Taylor, H. Svedhem, N. I. Ignatiev, W. J. Markiewicz, G. Piccioni, and P. Drossart, Atmospheric structure and dynamics as the cause of ultraviolet markings in the clouds of Venus, Nature, 456, 620-623, doi:10.1038/nature07466, 2008.

Toigo, A., P. J. Gierasch, and M. D. Smith, High resolution cloud feature tracking on Venus by Galileo, Icarus, 109, 318-336, 1994.

Tsang, C. C. C., P. G. J. Irwin, C. F. Wilson, F. W. Taylor, C. Lee, R. de Kok, P. Drossart, G. Piccioni, B. Bezard, and S. Calcutt, Tropospheric carbon monoxide concentrations and variability on Venus from Venus Express/VIRTIS-M observations, J. Geophys. Res., 113, E00B08, doi:10.1029/2008JE003089, 2008.

Ueno, M., Development of PtSi infrared camera for astronomical applications, SPIE, 2744, 84-91, 1996.

Woo, R., J. W. Armstrong, and A. Ishimaru, Radio occultation measurements of turbulence in the Venus atmosphere by Pioneer Venus, J. Geophys. Res., 85, 8031-8038, 1980.

Wood, J. A., Rock weathering on the surface of Venus, in Venus II, edited by S. Bougher, D. Hunten, and R. Phillips, University of Arizona Press, 1997.

Yamamoto, M. and H. Tanaka, Formation and maintenance of the 4-day circulation in the Venus middle atmosphere, J. Atmos. Sci., 54, 14721489, 1997.

Yamamoto, M. and H. Tanaka, The Venusian Y-shaped cloud pattern based on an aerosol-transport model, J. Atmos. Sci., 55, 1400-1416, 1998.

Yamamoto, M. and M. Takahashi, Superrotation and equatorial waves in a T21 Venus-like AGCM, Geophys. Res. Lett., 30, doi:10. 1029/2003GL016924, 2003.

Yamamoto, M. and M. Takahashi, Superrotation maintained by meridional circulation and waves in a Venus-like AGCM, J. Atmos. Sci., 63, 32963314, 2006.

Zasova, L., I. V. Khatountsev, N. I. Ignatiev, and V. I. Moroz, Local time variations of the middle atmosphere of Venus: solar-related structures, Adv. Space Res., 29(2), 243-248, 2002.

M. Nakamura (e-mail: nakamura.masato@jaxa.jp), T. Imamura, N. Ishii, T. Abe, T. Satoh, M. Suzuki, M. Ueno, A. Yamazaki, N. Iwagami, S. Watanabe, M. Taguchi, T. Fukuhara, Y. Takahashi, M. Yamada, N. Hoshino, S. Ohtsuki, K. Uemizu, G. L. Hashimoto, M. Takagi, Y. Matsuda, K. Ogohara, N. Sato, Y. Kasaba, T. Kouyama, N. Hirata, R. Nakamura, Y. Yamamoto, N. Okada, T. Horinouchi, M. Yamamoto, and Y. Hayashi 